NBER WORKING PAPER SERIES

\title{
GOVERNMENT PURCHASES OVER THE BUSINESS CYCLE: THE ROLE OF ECONOMIC AND POLITICAL INEQUALITY
}

\author{
Ruediger Bachmann \\ Jinhui Bai \\ Working Paper 16247 \\ http://www.nber.org/papers/w16247
NATIONAL BUREAU OF ECONOMIC RESEARCH
1050 Massachusetts Avenue
Cambridge, MA 02138

August 2010

We are grateful to seminar participants at Boston University, the Chicago FED, City U of Hong Kong, Georgetown, the Konstanz Seminar on Monetary Theory and Policy, Mannheim, Michigan, 2010 Midwest Macro Meeting, National U of Singapore, 2010 NBER-SI-PEPF, 2010 New York/Philadelphia Fed Quantitative Macro Workshop, 2010 SED, Yale, as well as Christopher House and Mark Huggett for their comments. We thank Marina Azzimonti and Davide Debortoli for their discussions. We would also like to thank Liz Accetta from the Census Bureau for giving us the historical data of the Annual Survey of State Government Finances, and Josh Montes for his excellent research assistance. The usual disclaimer applies. The views expressed herein are those of the authors and do not necessarily reflect the views of the National Bureau of Economic Research.

NBER working papers are circulated for discussion and comment purposes. They have not been peerreviewed or been subject to the review by the NBER Board of Directors that accompanies official NBER publications.

(C) 2010 by Ruediger Bachmann and Jinhui Bai. All rights reserved. Short sections of text, not to exceed two paragraphs, may be quoted without explicit permission provided that full credit, including $\odot$ notice, is given to the source. 
Government Purchases Over the Business Cycle: the Role of Economic and Political Inequality Ruediger Bachmann and Jinhui Bai

NBER Working Paper No. 16247

August 2010

JEL No. E30,E32,E60,E62,H30

\begin{abstract}
This paper explores the implications of economic and political inequality for the business cycle comovement of government purchases. We set up and compute a heterogeneous-agent neoclassical growth model, where households value government purchases which are financed by income taxes. A key feature of the model is a wealth bias in the political aggregation process. When calibrated to U.S. wealth inequality and exposed to aggregate productivity shocks, such a model is able to generate milder procyclicality of government purchases than models with no political wealth bias. The degree of wealth bias that matches the observed mild procyclicality of government purchases in the data, is consistent with cross-sectional data on political participation.
\end{abstract}

\author{
Ruediger Bachmann \\ Department of Economics \\ University of Michigan \\ Lorch Hall 365B \\ Ann Arbor, MI 48109-1220 \\ and NBER \\ rudib@umich.edu \\ Jinhui Bai \\ Department of Economics \\ Georgetown University \\ Washington, DC 20057-1036 \\ jb543@georgetown.edu
}




\section{Introduction}

This paper provides a quantitative theory of the implications of economic and political inequality for the business cycle comovement of government purchases. We define government purchases as "government expenditures on consumption and investment goods" as in the NIPA accounts, excluding transfers and interest payments. Notice that in many economic environments, where government purchases are a normal good, desired government purchases increase in aggregate productivity. The effect from aggregate productivity impacts economic agents in the same direction and will therefore, in isolation, lead to strongly procyclical government purchases. Government purchases are no different than private consumption expenditures in this respect. Unlike the decentralized private consumption choice, however, the choice of government purchases typically involves an aggregation of individual preferences. Economic and economically-based political inequality may thus be important for aggregate dynamics. The mechanism that we explore in this paper follows from two properties of standard models: individually desired government purchases, a normal good, increase in individual wealth. Therefore, if the political aggregation mechanism is such that in good economic times agents with lower individual wealth gain political influence compared to normal times, then the effect of individual wealth on desired government purchases might dampen the comovement of government purchases and output. We will refer to this effect as decoupling. The second feature is countercyclical wealth inequality. Agents with lower individual wealth gain more political in-

fluence in booms, if countercyclical wealth inequality is combined with a pro-wealth bias in the political decision.

It is well known that income and wealth inequality are an important feature of the U.S. economy (see Diaz-Gimenez et al. (1997) as well as Heathcote et al. (2010) for a comprehensive documentation of economic heterogeneity). A different literature provides direct evidence of wealth bias in political participation and argues that political inequality due to wealth bias is crucial in understanding the long-run relationship between economic inequality and public policies (see Rosenstone and Hansen, 1993, Benabou, 2000, Bartels, 2008, and Campante, 2008). In this paper, we ask whether the joint presence of economic and political inequality is also important for understanding certain aspects of the business cycle dynamics of public policies.

As a first step, we demonstrate the aforementioned two theoretical properties in a simple stylized model and show empirically, using political participation data from the American National Election Studies (ANES), that indeed lower income percentiles tend to have slightly procyclical relative political influence, whereas the opposite is the case for higher income percentiles. We also provide evidence that government purchases are a normal good. Together 
this means that the conditions for a decoupling of government purchases and the economic cycle are met, and indeed we find that government purchases are robustly the least procyclical component of aggregate demand. This holds for aggregate government purchases as well as for most disaggregated data.

In a second step, we ask whether the described mechanism with the interacting normality property of government purchases and countercyclical political inequality can also generate mild procyclicality of government purchases in a fully dynamic stochastic general equilibrium model that features quantitatively realistic economic and political inequality. We set up a stochastic neoclassical growth model with incomplete markets, where the equilibrium wealth distribution has a realistic concentration. Political inequality is linked to wealth inequality through the presence of a wealth bias in the political decision making process. We use a "political power"-weighted social welfare function to endogenously determine public policy. Otherwise, the model is essentially a merger of the representative household model in Klein et al. (2008) that features endogenous public policy, and the heterogeneous agent model in Krusell and Smith (1997 and 1998). This means we add to Klein et al. (2008) three features: aggregate uncertainty in the form of aggregate productivity shocks, economic heterogeneity in the form of persistent idiosyncratic shocks to labor productivity and - in the spirit of Krusell and Smith (1997 and 1998) - discount factors, and the parametric specification of political wealth bias from Benabou (2000). Our model features a government that cannot commit ex ante to a path of government purchases, but takes into account future streams of government purchases and how they depend on current decisions. The solution concept for the game between successive governments is the Markov-perfect equilibrium. Government purchases are financed by income taxes. Like Klein et al. (2008), we abstract from government debt and transfers.

We find that the contemporaneous correlation between output and government purchases is a declining function of the wealth bias in the political system. The degree of wealth bias that matches this correlation in the data is broadly in line with the campaign contribution shares by income percentiles reported in the ANES data. We also show that either a lack of political inequality or a lack of quantitatively realistic wealth inequality, the extreme case of which is a representative agent version of our model, means that output and government purchases are too strongly correlated, compared to the data. Models that lack either type of inequality have essentially approximate aggregation in the sense of Krusell and Smith (1998) and behave very similarly to the representative agent case. ${ }^{1}$ Current government purchases in such models are

\footnotetext{
${ }^{1}$ Thus one contribution of our paper is to compute and analyze successive extensions of the Klein et al. (2008) model of time-consistent government policy with aggregate uncertainty and economic and political heterogeneity. Numerically, we use the algorithm in Krusell and Smith (1998) and show that approximating the wealth distribution and its law of motion by a finite number of moments can also be applied to politico-economic equilibrium models with uninsurable labor income risk and aggregate shocks. We also provide new findings as to which classes
} 
mainly determined by the intertemporal trade-off between private and government consumption today and tomorrow, the wealth effect from aggregate productivity. By contrast, a very unequal wealth distribution intensifies disagreement about the optimal level of government purchases that, if funneled through political inequality, can cause a partial decoupling of aggregate government purchases and output. As in the data, in the model the political weight of the wealth-poorest is procyclical and that of the wealth-richest is countercyclical. To be clear: we do not mean to say that ours is the only conceivable mechanism that could explain the mild procyclicality of government purchases. ${ }^{2}$ But in standard economic environments it is a consequence of quantitatively realistic economic and political inequality.

\section{Related Literature}

Besides the intrinsic link to the literature on wealth heterogeneity and political wealth bias, our paper is most closely related to the literature on endogenous government purchases in dynamic environments. This is a quantitative macro literature that starts from an otherwise standard neoclassical growth model and uses a Markov-perfect equilibrium concept to endogenize government purchases (see Klein et al., 2008, Azzimonti, 2009, and Debortoli and Nunes, 2010). This literature has so far focussed mostly on long-run steady state analyses, and has also abstracted from economic or political heterogeneity. Recently, Battaglini and Coate (2008b) and Azzimonti et al. (2008), building on earlier work in Battaglini and Coate (2008a), have developed a general framework to characterize fiscal policies under legislative bargaining and with aggregate uncertainty. This literature does not have the neoclassical growth model set up in its economic part. For instance, they use a utility function that is linear in private consumption, they abstract from capital accumulation and wealth inequality which is the central focus of our framework. While this literature is much richer than our paper in some dimensions in that it deals with multidimensional government policies, these simplifications might limit its usefulness for quantitative analysis. In addition, we complement their work by studying the dynamics of government purchases in a probabilistic voting and a majority voting environment.

of heterogeneous agent models feature approximate aggregation. Conversely, we provide a realistically calibrated, quantitative example with at least a small quantitative deviation from approximate aggregation in the sense of Krusell and Smith (1998). Indeed, our equilibrium laws of motion contain the Gini coefficient of the wealth distribution in addition to the average wealth. We show that introducing this higher moment into the equilibrium laws of motion slightly changes the equilibrium dynamics of the model, especially the comovement between output and government purchases.

${ }^{2}$ Debortoli and Nunes (2010), using a representative agent model, introduce an additional aggregate shock in the political system and find a lower contemporaneous correlation between government purchases and output than in models with one aggregate shock. 
In addition, our paper is also related to three other strands of the literature. Methodologically, we build on the framework developed in the literature on dynamic political economy, e.g., Krusell et al. (1997), Krusell and Rios-Rull (1999), Hassler et al. (2003), Hassler et al. (2005), Song et al. (2007), Corbae et al. (2009), Bai and Lagunoff (2010). Secondly, this paper complements the literature on procyclical fiscal policy in developing countries that focuses on international aspects such as sovereign borrowing constraints and dysfunctional democracy (see Ilzetzki (2007), Alesina et al. (2008), and Ilzetzki and Vegh (2008) for an overview). Thirdly, our paper is related to the literature with fiscal policy in incomplete markets, such as Heathcote (2005) and Gomes et al. (2008).

The remainder of the paper proceeds as follows: section two sets up the economic environment and, with the help of a simple model, describes the main causal mechanism behind decoupling. It also provides data evidence behind this mechanism. Section three describes the equilibrium concept, the political aggregation mechanism, computation and calibration of the quantitative model. Section four presents the results from numerical simulations and some robustness checks. Proofs, more facts about government purchases, computational and numerical details are relegated to several appendices.

\section{Motivation: Simple Models - Stylized Facts}

In this section, we describe the main mechanism by which economic and political inequality influence the dynamics of government purchases in the fully-fledged quantitative and dynamic model in Section 3. We first show in a simple static model that in a standard economic environment desired government purchases of an arbitrary economic agent are an increasing function of aggregate productivity and individual wealth. The response to aggregate productivity makes government purchases positively correlated with output and private consumption. If the political aggregation mechanism is such that in booms wealth-poorer agents gain political influence compared to normal times, then the effect of individual wealth on desired government purchases might dampen the comovement of government purchases and output. Our second result concerns the cyclicality of wealth inequality. We show in a two-period version of the static model that if the third derivative of the consumption felicity function is positive then under some conditions wealth inequality can be expected to be countercyclical. If this result is coupled with a pro-wealth bias in the political decision about government purchases, then agents with lower individual wealth will gain more political influence in booms. We then provide stylized facts from data that support decoupling as well as the sketched causal mechanism. 


\subsection{Simple Models}

\subsubsection{A One-Period Model}

Let us first study the (hypothetical) decision problem of an agent who values private consumption, $c$, and government purchases, $G$. The agent is endowed with $\tilde{l}$ units of time, labor productivity, $\epsilon$, and an initial capital stock, $k$, which depreciates at rate $\delta$. The agent receives factor income from competitive capital rental and labor markets, subject to a linear income tax, at rate $\tau(G)$, which is a function of government purchases.

$$
\max _{c, G} U(c, G) \equiv \theta u_{1}(c)+(1-\theta) u_{2}(G), \text { such that } c=(1-\delta) k+(1-\tau(G))(w \tilde{l} \epsilon+r k)
$$

$0<\theta<1$, and $u_{1}(c)$ as well as $u_{2}(G)$ are increasing, strictly concave and differentiable functions. Notice that we write this problem as if the agent were to decide about both private consumption and government purchases. This will in general not be the case. Instead, $G$ will be decided in a political aggregation mechanism, through a constitution (see Sections 3.2 and 3.3). However, this hypothetical decision problem allows us to introduce the concept of privately desired government purchases, $\hat{G}$.

To close the model, we assume that the economy is populated by a continuum of such agents with potentially different labor productivities and capital stock endowments, that there exists an aggregate Cobb-Douglas constant-returns-to-scale technology to produce output and that the government has to balance its budget:

$$
\begin{gathered}
Y=z K^{\alpha} L^{1-\alpha}, \text { where } K=\int_{0}^{1} k_{i} d i \text { and } L=\tilde{l} \int_{0}^{1} \epsilon_{i} d i \\
\tau(K, L, z, G)=\frac{G}{z K^{\alpha} L^{1-\alpha}} .
\end{gathered}
$$

$z$ is an aggregate productivity shock and the only source of aggregate uncertainty. Competitive factor markets guarantee the usual factor price conditions: $w(K, L, z)=(1-\alpha) z(K / L)^{\alpha}$ and $r(K, L, z)=\alpha z(K / L)^{\alpha-1}$.

A re-write of the budget constraint illustrates the sources of conflicting policy preferences. Plugging the tax function $\tau(K, L, z, G)$ into the budget constraint and re-arranging terms, yields:

$$
c+p(k, \epsilon ; K, L) G=(1-\delta) k+p(k, \epsilon ; K, L) z K^{\alpha} L^{1-\alpha},
$$

where

$$
p(k, \epsilon ; K, L) \equiv \frac{w(K, L, z) \tilde{l} \epsilon+r(K, L, z) k}{z K^{\alpha} L^{1-\alpha}}=(1-\alpha) \frac{\tilde{l} \epsilon}{L}+\alpha \frac{k}{K}
$$


can be viewed as the individual-specific relative price of $G$ measured in units of private consumption for a household with characteristic $(k, \epsilon)$. From this perspective, the decision problem falls into the framework of classical Consumer Demand Theory, where the agents face a given relative price $p(k, \epsilon ; K, L)$ and endowment $\left\{(1-\delta) k, z K^{\alpha} L^{1-\alpha}\right\}$ of two commodities, $c$ and $G$. The relative price does not depend on aggregate technology, because $z$ proportionally increases the income of every household and hence brings no change in relative income.

The effect of a change in $z$ and $k$ on the private demand for $G$, denoted by $\widehat{G}(k, \epsilon ; K, L, z)$, can now be readily analyzed and summarized in the following ${ }^{3}$

Proposition $1 \widehat{G}(k, \epsilon ; K, L, z)$ is strictly increasing in $z$. If $u_{1}(c)$ has the CRRA form, $\frac{c^{\gamma}}{\gamma}, \gamma \leq 0$ and $\delta \leq 1$, with one inequality holding strictly, then $\widehat{G}(k, \epsilon ; K, L, z)$ is strictly increasing in $k$. In the case of linear consumption felicity, $\gamma=1, \widehat{G}(k, \epsilon ; K, L, z)$ is strictly decreasing in $k$, while it does not change in $z$.

The intuition behind this result is that with $\gamma=1$ there is no income effect, so an increase in individual capital holdings through an increase in the relative price of government purchases will only lead to a substitution effect. The lower $\gamma$, the stronger the income effect that makes agents want to demand more $G$. The proposition is important because it predicts for parameters that are standard in quantitative macroeconomics that wealth-richer agents demand more government purchases.

The proposition highlights two channels for the dynamics of government purchases over the business cycles. A higher technology shock tends to increase $G$, which in isolation makes $G$ procyclical. This productivity-induced wealth effect does not require heterogeneity of agents. It is present even if all agents are the same. But heterogeneity in capital endowments may generate an additional channel if wealth inequality changes over the business cycles and the political system exhibits a wealth bias in the aggregation of preferences over government purchases. For instance, with a pro-wealth bias, a decrease in wealth inequality operating through a similar change in political inequality might move the policy outcome towards the preference of poorer people, hence-assuming $\widehat{G}(k, \epsilon ; K, L, z)$ increases in $k$-towards a lower level of $G$. Other things equal, the higher the wealth bias, the larger is this effect. Compared to a representative agent model with only the productivity-induced wealth effect present, countercyclical wealth inequality would then dampen the positive comovement of $G$ with the economic cycle. In the next subsection we extend the model to two periods, allowing for a nontrivial saving decision, and argue that with a positive third derivative of the consumption felicity function, there is a tendency in such models to produce countercyclical wealth inequality.

\footnotetext{
${ }^{3}$ Proofs of Proposition 1 and Proposition 2 can be found in Appendix A.
} 


\subsubsection{A Two-Period Model}

In this subsection we focus on the relation between aggregate economic conditions and wealth inequality in a simple two-period production economy. Agents discount the future at rate $\beta$ and use flow utility (1). The budget constraint now reads, suppressing for ease of notation the dependence of $w, r$ and $\tau$ on macro variables:

$$
c+k^{\prime}=(1-\delta) k+(1-\tau)(w \tilde{l} \epsilon+r k)
$$

The following proposition shows that under certain conditions and in a certain sense it can be shown analytically that our two-period production economy features countercyclical wealth inequality.

Proposition 2 If $u_{1}(c)$ has a positive third derivative, hence in particular for a CRRA specification, an exogenous increase in today's real wage (keeping other macro variables constant), decreases the Gini coefficient of second-period capital holdings for a group of agents with the same labor productivity, but different initial capital holdings.

It is instructive to discuss the conditions in the statement of the proposition in turn. The positive third derivative of consumption felicity is a standard assumption in quantitative macroeconomics and needs no further comment. The scenario we have in mind is to "simulate a boom" through an exogenous increase in the real wage in a partial equilibrium environment. Of course, in a micro-founded general equilibrium model this can only be brought about through a change in an exogenous variable, typically aggregate productivity $z$. However, the statement cannot analytically be shown to hold for increases in aggregate productivity, for two reasons. First, aggregate productivity increases lead, via changes in aggregate capital accumulation, to changes in tomorrow's factor prices. Secondly, even ignoring these general equilibrium effects, we show in the proof of the proposition that simultaneous changes in $w$ and $r$ lead in general to ambiguous effects on inequality. Finally, the analytical derivation of our statement requires that inequality in second-period capital holdings is generated by a specific source of heterogeneity, namely different initial capital holdings. We found it impossible to derive a clear statement in the presence of higher dimensional heterogeneity.

Nevertheless, the proposition shows that in the class of models we study there exists at least one force towards countercyclical wealth inequality. It is a quantitative question, whether this force will prevail in a fully-fledged dynamic and realistically calibrated model. This justifies our use of numerical methods. 


\subsection{Stylized Facts}

In this subsection, we first show that government purchases are procyclical, but less so than any other component of domestic aggregate demand. We then provide further, cross-sectional evidence from U.S. state data that government purchases are a normal good. We finish by showing that political inequality as measured by voter turnout and the incidence of campaign contributions by income percentiles is not only prevalent in the U.S., but also mildly countercyclical. This is micro evidence in support of the decoupling mechanism.

Figure 1 shows the cyclical components of two measures of annual government purchases on goods and services alongside the cyclical component of U.S. GDP. ${ }^{4}$ We study government consumption and gross investment including defense spending $(G)$, and government nondefense consumption and gross investment $(G N D)$. Both measures of government purchases are clearly procyclical.

Figure 1: Cyclicality of Government Purchases

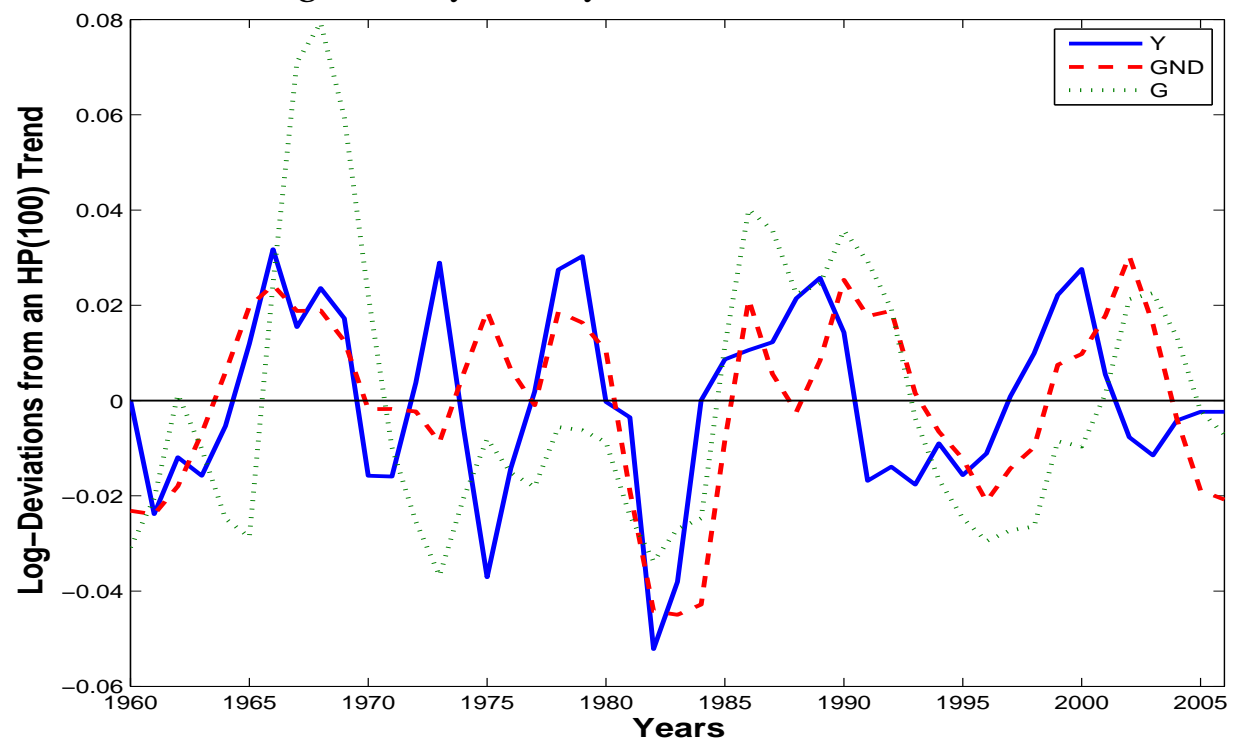

Notes: $Y$ denotes GDP, G government consumption and gross investment expenditures and GND government nondefense consumption and gross investment expenditures. All variables are annual, they range from 19602006. They are deflated by their corresponding deflators, logged and filtered with a Hodrick-Prescott filter with smoothing parameter 100.

We complement the graphical analysis by a second moment analysis in Table 1. Government purchases are the least procyclical component of domestic aggregate demand. In particular, private consumption expenditures are much more correlated with aggregate output than

\footnotetext{
${ }^{4}$ Annual data on government purchases correspond closely to the yearly nature of government budgeting and therefore we focus on this frequency. Quarterly data on government purchases display a similar decoupling property. We start our analysis in 1960 to exclude the Korean war.
} 
government purchases. This is also reflected in a relatively low correlation coefficient of government purchases with private consumption expenditures and the (mild) countercyclicality of the government-purchases-to-GDP-ratio. Two additional properties of government purchases dynamics can be seen from Table 1. Unlike the other two components of aggregate demand, the dynamic correlations of government purchases with lagged output are higher than the contemporaneous correlations. Secondly, government purchases are the most persistent component of domestic aggregate demand, and they are also more persistent than output.

Table 1: Business CyCle Facts of Government PurChases

\begin{tabular}{lcccc}
\hline \hline Moment & Correl. w. Y & Correl. w. Y-Lag. & Correl. w. C & Autocorrel. 1st-order \\
\hline$Y$ & 1.00 & 0.54 & 0.87 & 0.54 \\
$C$ & 0.87 & 0.41 & 1.00 & 0.62 \\
$I$ & 0.84 & 0.21 & 0.69 & 0.42 \\
$G N D$ & 0.47 & 0.58 & 0.49 & 0.74 \\
$G$ & 0.35 & 0.51 & 0.35 & 0.79 \\
$\frac{G N D}{Y}$ & -0.23 & 0.12 & -0.14 & 0.74 \\
$\frac{G}{Y}$ & -0.11 & 0.13 & -0.09 & 0.86 \\
\hline
\end{tabular}

Notes: see notes to Figure 1. C denotes private consumption expenditures and I private gross fixed investment. All variables are annual, they range from 1960-2006. They are deflated by their corresponding deflators. All variables except the ratios are logged and filtered with a Hodrick-Prescott filter with smoothing parameter 100. $\frac{G N D}{Y}$ and $\frac{G}{Y}$ are linearly detrended.

These stylized facts about the dynamics of government purchases hold more generally. They hold along the consumption/investment distinction, along political subdivisions - federal versus state and local governments - and when government purchases are disaggregated into defense and nondefense spending. Government employment behaves similarly to government purchases. They also hold along the functional disaggregation from NIPA table 3.15.5. Finally, the government purchases of most of the 50 U.S. states are mildly positively correlated with the cyclical component of the state's GDP. And the correlation of the states' $G$ with their lagged output typically exceeds the contemporaneous correlation. ${ }^{5}$

As is evident from both the aggregate and disaggregated data, the procyclical movement of government purchases suggests that it is a normal good: as income increases, the demand for government purchases rises. This fact can also be seen from the cross-sectional variation across U.S. states. Average government purchases comove positively with per capita state-level GDP,

\footnotetext{
${ }^{5}$ See Tables 7 and 8 as well as Figures 8 and 9 in Appendix B. The two most noticeable exceptions are federal nondefense purchases, which is only roughly $12 \%$ of all purchases and acyclical, and, along the functional disaggregation, health spending, which is roughly $4.5 \%$ of total government purchases and mildly countercyclical.
} 
when we control for the states' surface and population. ${ }^{6}$ This shown in Figure $2 .{ }^{7}$

Figure 2: The Correlation Between States' GDP Per Capita and Government Purchases
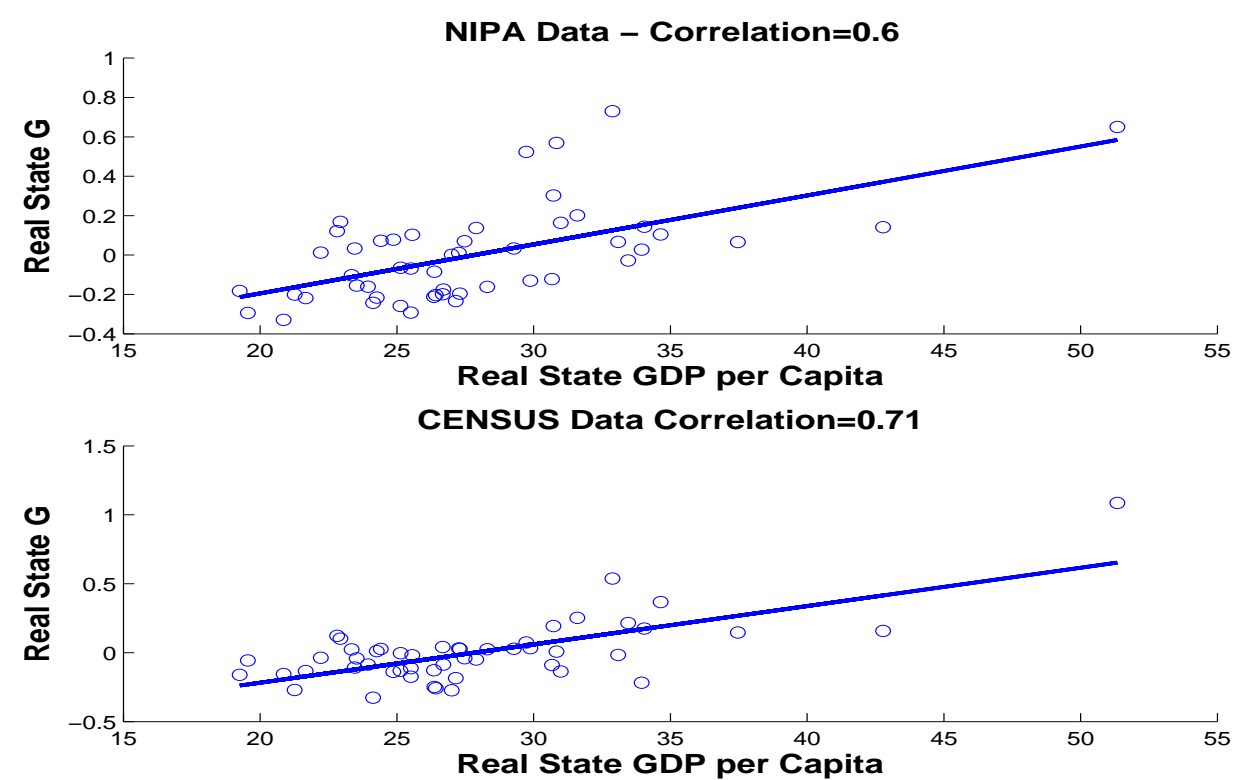

Notes: 'Real State G' in the upper panel is real GDP from the total government sector in the regional NIPA data. 'Real State G' in the lower panel is the sum of the expenditures on 'Total Current Operations' and 'Total Capital Outlays' from the historical data of the census of state government finances, deflated by the state-specific implicit deflator for government GDP from the NIPA data. 'Real State GDP per capita' is real GDP from the regional NIPA data. All data are averaged across time. These averaged 'Real State G' data are regressed on the states' total surface and population. The residuals of these regressions are displayed against 'Real State GDP per capita'.

We finish this section by providing some direct evidence on the presence of pro-wealth (or rather pro-income) bias in the political process, using political participation data. In Table 2 we report the fraction of people who vote and make campaign contributions and belong to a certain percentile of the income distribution. ${ }^{8}$ For instance the richest $5 \%$ represent $6.7 \%$ of

\footnotetext{
${ }^{6}$ It is reasonable to assume that states with a larger surface have different transportation needs, which is why we control for the states' surface. The effect of including this control is, however, quantitatively small. We also control for population because part of the government purchases in the data may include partially rival goods. Figure 10 in Appendix B takes the opposite view, i.e. completely non-rivalrous government purchases, and repeats the same exercise for the raw data on state-level government purchases and per capita state-level GDP without any controls. We still find a positive correlation, albeit somewhat mitigated.

${ }^{7}$ Figure 11 in Appendix B repeats the same exercise as in Figure 2 with essentially the same results for the state and local government sector in the regional NIPA data, and for the census data, disaggregated for 'Total Current Operations' (consumption) and 'Total Capital Outlays' (investment). Also, one may wonder whether the positive correlation between per capita state-level GDP and state-level government purchases is simply driven by the rightmost data point, the state with the highest per capita income on average, Alaska. In a robustness check, where we exclude Alaska and Delaware (the second richest state), we show that this is not the case, although quantitatively the positive connection is reduced: the correlation for NIPA data goes down to 0.44 , the one for Census data decreases to 0.36 .

${ }^{8}$ The somewhat nonstandard partition of the income distribution is given by ANES. We start from the same data source as Rosenstone and Hansen (1993) and Benabou (2000) in his table 1, but use a somewhat different
} 
voters and $17.5 \%$ of campaign contributors. In contrast, the poorest $16 \%$ make up only $13.1 \%$ of voters and $5 \%$ of campaign contributors. Given a strong positive correlation between income and wealth, the data also suggests an underlying pro-wealth bias in the political system, i.e., a positive correlation between wealth and political representation. To the extent that richer people give a larger amount when they do contribute to political candidates, the participation rate data of campaign contributions, which represents only an extensive margin, may well underestimate the actual inequality in political influence. The suggested pro-wealth participation pattern in the data motivates our model specification with a built-in positive link between wealth and political power.

Table 2: Political PARTiCiPATION PER InCOME GrouP

\begin{tabular}{lccccc}
\hline \hline Income Percentile & {$[0-16 \%]$} & {$[17-33 \%]$} & {$[34-67 \%]$} & {$[68-95 \%]$} & {$[96-100 \%]$} \\
\hline Voting shares & $13.1 \%$ & $14.4 \%$ & $33.6 \%$ & $32.2 \%$ & $6.7 \%$ \\
Campaign contribution shares & $5.0 \%$ & $8.1 \%$ & $27.5 \%$ & $41.9 \%$ & $17.5 \%$ \\
\hline
\end{tabular}

Notes: 'Voting shares' are the average fractions of voters that belong to a certain percentile of the income distribution. 'Campaign contribution shares' are the average fractions of campaign contributors that belong to a certain percentile of the income distribution. Data source is the American National Election Studies (ANES). See Rosenstone and Hansen (1993), Appendix B, for a precise wording of the survey questions. We use data from 1960-2000.

We report the comovement properties of the measured inequality in political participation in Table 3. The correlation patterns of the lowest and highest percentile are at least consistent with countercyclical political inequality. During an economic boom, the political representation for the lower-income (higher-income) group displays a tendency to rise (decrease). As a result, the political representation shifts slightly from the higher tail to the lower tail of the income distribution during good times, and vice versa. Our preferred specification of the quantitative model will also exhibit these rather small positive correlation numbers for the lower income percentiles and rather small negative correlation numbers for the higher income percentiles.

time horizon, 1960-2000, which explains the very small quantitative differences in our results. We had access until the 2004 data of the ANES, but the 2002 data along income percentiles were missing, which is why we restrict the analysis to $1960-2000$. 
Table 3: Cyclicality of Political Participation Per Income Group

\begin{tabular}{lcc}
\hline \hline Income Percentile & {$[0-16 \%]$} & {$[96-100 \%]$} \\
\hline Voting Shares & & \\
\hline Correl. w. Y & 0.14 & -0.05 \\
Correl. w. GND & 0.24 & -0.21 \\
Correl. w. G & 0.18 & -0.45 \\
\hline Campaign Contribution Shares & & \\
\hline Correl. w. Y & 0.08 & -0.22 \\
Correl. w. GND & 0.22 & -0.11 \\
Correl. w. G & 0.32 & -0.24 \\
\hline
\end{tabular}

Notes: see notes to Figure 1 and Table 2. Since the ANES data are only biannual, we filter the annual data for $Y$, $G$ and GND first and then use only the biannual deviations from trend.

\section{The Quantitative Model}

In this section, we build on the model from Section 2.1 and use numerical methods to study a calibrated dynamic stochastic general equilibrium model with heterogeneous agents and quantitatively realistic economic and political inequality. We first briefly add what is necessary to specify the economic environment in this quantitative model. Then we define the equilibrium concept with endogenous public policy. The ensuing subsection describes the political aggregation mechanism. We finish with a discussion of the computation and calibration of the model.

\subsection{The Dynamic Economic Environment}

Section 2 specified the main ingredients of a standard heterogeneous household stochastic growth model, as in Krusell and Smith (1998). In the fully dynamic economy, infinitely lived households face persistent idiosyncratic shocks to their labor efficiency, $\epsilon$. This leads to idiosyncratic labor income risk to which households partially insure using physical capital as the only asset. Idiosyncratic labor efficiency shocks are a standard assumption in the incomplete markets literature (see, e.g., Huggett, 1993, and Aiyagari, 1994), because they give rise to a nondegenerate wealth distribution. In order to generate quantitatively realistic wealth inequality, we again follow Krusell and Smith (1998) and assume that households face persistent idiosyncratic shocks to their discount factor. We will show that matching the inequality in the U.S. wealth distribution is crucial for understanding the dynamics of government purchases in our model. We finally specify the felicity function (1) as a log-log form: 


$$
U(c, G)=\theta \log (c)+(1-\theta) \log (G) .
$$

The budget constraint is given by (6), with an additional borrowing constraint $k_{i}^{\prime} \in[\underline{k},+\infty)$. We assume that the two sources of heterogeneity, $\epsilon$ and $\beta$, evolve according to discrete Markov chains, independently of each other and across agents. ${ }^{9}$ Similarly, $z$, i.e. aggregate productivity, evolves according to a discrete Markov chain, which is independent from the two Markov processes that govern the idiosyncratic stochastic environment.

\subsection{Dynamic Equilibrium with Endogenous Public Policy}

In choosing government purchases, $G$, the government faces - on top of the balanced budget requirement - two institutional constraints. First, the government chooses $G$ under the constraints of social choice institutions. Some examples of social choice institutions are the utilitarian social planner and a majority voting system, although we are going to study more general mechanisms in the next subsection. For the purpose of defining an equilibrium, however, we present the constraint as an abstract social preference aggregator, $W\left(\left\{J_{i}\right\}_{i \in[0,1]}\right)$, which maps the preferences of each household, $J_{i}$, to the equilibrium choice. $J_{i}$ denotes in net present value terms the indirect utility function of each household over alternative policy proposals. It is formally defined below.

Second, the government cannot commit to a stream of future policies. Without a commitment device, it is well known that the commitment equilibrium in our environment is not timeconsistent. Time consistency requires imposing a subgame-perfect restriction with successive governments and the households as game players. Following Krusell and Rios-Rull (1999) and Klein et al. (2008), we focus on a subclass of subgame-perfect equilibrium with Markov strategies, i.e., Markov-perfect Equilibrium (MPE). ${ }^{10}$ Adapted to our heterogeneous agent environment, the aggregate state variables consist of the technology shock, $z$, and the joint distribution over the pair $\left(k_{i}, \epsilon_{i}, \beta_{i}\right)$, denoted by $\Gamma$. With the choice of these state variables, the MPE is defined in terms of continuation value functions and best response functions under a one-shot deviation. Loosely speaking, MPE is achieved if these objects satisfy standard requirements of Recursive Competitive Equilibrium (RCE) on the equilibrium path, and best-response consistency on the off-equilibrium path. The formal definition follows.

\footnotetext{
${ }^{9}$ Since $\epsilon$ is uncorrelated across households, and by the continuum assumption, $L$ is a constant owing to the law of large numbers. We therefore suppress it as an argument in the real wage, the real interest rate and the tax function.

${ }^{10}$ By construction, this class of Markov-perfect Equilibrium rules out the reputational equilibria with historydependent strategies. For examples of equilibria with trigger strategy and reputation, see Aguiar and Amador (2009). For studies of constrained efficient policies with political economy frictions, see Acemoglu, Golosov and Tsyvinski (2009), Farhi and Werning (2008), and Yared (2010).
} 
Definition 1 A Markov-perfect Equilibrium for the economy is a set of functions, including a government policy function $G=\Psi(\Gamma, z)$, a distribution transition function $\Gamma^{\prime}=H(\Gamma, z, G)$, an equilibrium continuation value function $v(k, \epsilon, \beta, \Gamma, z ; \Psi, H)$, a best-response value function $J(k, \epsilon, \beta, \Gamma, z, G ; \Psi, H)$ and a best-response decision rule $k^{\prime}=h(k, \epsilon, \beta, \Gamma, z, G ; \Psi, H)$, such that

(a) For any given $G$, the functions $J(k, \epsilon, \beta, \Gamma, z, G ; \Psi, H), \quad v(k, \epsilon, \beta, \Gamma, z ; \Psi, H)$ and $h(k, \epsilon, \beta, \Gamma, z, G ; \Psi, H)$ solve the household's problem

$$
\begin{aligned}
J(k, \epsilon, \beta, \Gamma, z, G ; \Psi, H)= & \max _{\left\{c, k^{\prime}\right\}}\left\{U(c, G)+\beta E\left[v\left(k^{\prime}, \epsilon^{\prime}, \beta^{\prime}, \Gamma^{\prime}, z^{\prime} ; \Psi, H\right) \mid \epsilon, z\right]\right\} \\
& \text { s.t. } \\
& c \geq 0, k^{\prime} \geq \underline{k}, \\
& c+k^{\prime}=(1-\delta) k+(1-\tau(K, z, G))(w(K, z) \tilde{l} \epsilon+r(K, z) k), \\
& \Gamma^{\prime}=H(\Gamma, z, G) .
\end{aligned}
$$

In addition, $v(k, \epsilon, \beta, \Gamma, z ; \Psi, H)=J(k, \epsilon, \beta, \Gamma, z, \Psi(\Gamma, z) ; \Psi, H)$.

(b) $H(\Gamma, z, G)$ is implied by $h(k, \epsilon, \beta, \Gamma, z, G ; \Psi, H)$ and the exogenous stochastic processes.

(c) $\Psi(\Gamma, z)$ is a result of social choice, i.e., $\Psi(\Gamma, z)=W\left(\left\{J\left(k_{i}, \epsilon_{i}, \beta_{i}, \Gamma, z, G ; \Psi, H\right)\right\}_{i \in[0,1]}\right)$.

The first part of the equilibrium definition says that $h$ is the best response of the household to an arbitrary change in current $G$ when the future follows the equilibrium path, a so-called one-shot deviation best response. $J$ denotes the corresponding value function. In addition, the best-response value function should coincide with the equilibrium continuation function when evaluated at the equilibrium policy $G=\Psi(\Gamma, z)$. The second part requires that the evolution of the aggregate distribution, $H(\Gamma, z, G)$, is generated by the households' best responses for any given $G$ and the exogenous stochastic processes. This reflects rational expectations on the household side. On the equilibrium path, this requirement reduces to the familiar consistency restriction in RCE. In addition, MPE imposes the same requirement for off-equilibrium paths. The third part imposes the constraint from the social choice institution.

Notice that when there is only a representative type of household who faces aggregate shocks, our economy reduces to a stochastic growth version - i.e. without labor/leisure choice - of Klein et al. (2008). 


\subsection{The Social Choice Mechanism}

In our baseline model, the public choice mechanism is defined as

$$
\Psi(\Gamma, z)=\arg \max _{G}\left\{\int_{0}^{1}\left(k_{i}^{+}\right)^{\chi} J\left(k_{i}, \epsilon_{i}, \beta_{i}, \Gamma, z, G ; \Psi, H\right) d i\right\}
$$

where $\chi \in \mathbb{R}$ is a given institutional parameter reflecting characteristics of the political process and $k_{i}^{+} \equiv \max \left[0, k_{i}\right] .{ }^{11}$ The government chooses public policy so as to maximize a weighted social welfare function, with weights dependent on the wealth of the households. The weighting function, $\left(k_{i}^{+}\right)^{\chi}$, is meant to be a flexible parametric form to capture wealth bias in the political process. If $\chi=0$, every household is treated equally, which leads to the familiar egalitarian social welfare function. A positive (negative) value of $\chi$ implies a pro-wealth (anti-wealth) bias in the political process, since a larger (smaller) weight is assigned to a household with a higher positive wealth. As the absolute value of $\chi$ increases, the degree of wealth bias becomes larger. Intuitively, a higher wealth bias increases the responsiveness of political weights to wealth inequality, hence implies a higher political inequality. In fact, this intuition can be proved formally when the political inequality is measured in terms of the Lorenz curve (see Bai and Lagunoff, 2009, for a formal proof and a general characterization of related weighting functions).

There are different interpretations of our baseline public choice mechanism. From a normative aspect, the weighted social welfare function approach can be viewed as a social planner's problem. As we show in Appendix $\mathrm{C}$, there is also a micro-founded positive interpretation, which is generated by a political process in a probabilistic voting environment. ${ }^{12}$ There the weighting function, $\left(k_{i}^{+}\right)^{\chi}$, can be attributed to a pro-wealth vote allocation in a weighted voting system. We thus extend the well-known result in the literature that political decision making via a standard unbiased utilitarian welfare function is equivalent to probabilistic voting (see Lindbeck and Weibull, 1987) to a dynamic set up and the case of wealth-biased probabilistic voting.

\footnotetext{
${ }^{11}$ See Benabou (2000) and Bai and Lagunoff (2009). Using $k_{i}^{+}$is a convenient way to avoid negative weights in the welfare function. We also experimented with a weighting function that depends on total available resources, $\left(k_{i}-\underline{k}\right)^{\chi}$, and found that the results are not dependent on this functional form.

${ }^{12}$ In Section 4.2 we study a pro-wealth majority voting environment.
} 


\subsection{Computation}

Whether the partial decoupling mechanism outlined in Section 2 is economically significant, is a quantitative question. We thus use numerical methods to characterize and analyze the Markov-perfect equilibria of our economy. In computing the equilibria, we face the usual practical challenges introduced by the heterogeneous-agent economic environment, as well as new complications due to the endogenous policy determination.

On a conceptual level, we need to adapt the fixed-point iteration procedure used in computing RCE to account for the best-response consistency of off-equilibrium paths. As already intimated in our equilibrium definition, our procedure iterates on the best response transition function and policy function $(H, \Psi)$ to reach a fixed point. Both on and off equilibrium restrictions are honored in every step of the computation.

On a practical level, we have to specify a set of moments of the wealth distribution and functional forms for $(H, \Psi)$ to implement the general procedure proposed in Krusell and Smith (1998). They find that average capital is sufficient to approximate the infinite-dimensional wealth distribution and its law of motion and, thus, to forecast future prices. In our case, because of the public choice nature of fiscal policy higher-order statistics might matter for the evolution of the economy. This intuition is verified in our simulations. We find that the combination of average capital and the Gini coefficient of the capital distribution is sufficient to characterize the evolution of our economy, yet at the same time keeps the dimensionality of the problem tractable. ${ }^{13}$ The computed fixed point of $H$ then takes the following form: ${ }^{14}$

$$
\begin{aligned}
\log K^{\prime} & =a_{0}(z)+a_{1}(z) \log K+a_{2}(z) \log \operatorname{Gini}(k)+a_{3}(z) \log G+a_{4}(z)(\log G)^{2}, \\
\log \operatorname{Gini}\left(k^{\prime}\right) & =\widetilde{a}_{0}(z)+\widetilde{a}_{1}(z) \log K+\widetilde{a}_{2}(z) \log \operatorname{Gini}(k)+\widetilde{a}_{3}(z) \log G+\widetilde{a}_{4}(z)(\log G)^{2},
\end{aligned}
$$

and that of $\Psi$ takes the form of

$$
\log G=b_{0}(z)+b_{1}(z) \log K+b_{2}(z) \log \operatorname{Gini}(k)
$$

Notice that the parameters of these equations depend on the (discrete) level of aggregate productivity. We solve the MPE using a fixed point iteration procedure from the parameters in (9)-(11) onto themselves. The computational algorithm is outlined in detail in Appendix D. The parameterized Krusell and Smith rules and their performance are shown in Appendix F.

\footnotetext{
${ }^{13}$ We also experimented with the standard deviation of the wealth distribution, but found better R2 improvements with the Gini coefficient.

${ }^{14}$ It turns out that $(\log G)^{2}$ improves the fit of the law of motion for capital significantly.
} 


\subsection{Calibration}

The model is calibrated to match features of the U.S. economy from 1960 to 2006. Annual data on government purchases correspond closely to the yearly nature of government budgeting and therefore we calibrate our model to this frequency. This choice immediately implies three parameter selections: the depreciation rate, $\delta$, is set to 0.1 ; the discount rate, $\beta$, is centered around 0.96; and we model aggregate productivity, $z$, as a five-state Markov chain that approximates a $\log$-AR(1) process with an autocorrelation coefficient of 0.8145 and conditional standard deviation of 0.0165 . This standard deviation is chosen to make our models approximately match the annual percentage standard deviation of GDP in the data, $1.90 \%$. This paper is not about explaining output volatility from a measured exogenous shock series, as in the RBC tradition which uses fluctuations in the Solow residual to generate a large part of observed output fluctuations. Rather, this paper is concerned with shedding light on the comovement properties of government purchases and the overall economic cycle, given the right output volatility. The final standard parameter is the output elasticity of capital, $\alpha=0.36$.

Idiosyncratic labor efficiency, $\epsilon$, is modeled as a nine-state Markov chain that approximates a log-AR(1) process with an autocorrelation coefficient of 0.75 and conditional standard deviation of 0.18 . These numbers are broadly consistent with the estimates from Guvenen and Smith (2008) who use an indirect inference approach and data on labor income, labor supply and consumption to estimate a model for the natural logarithm of labor income. We set $\tilde{l}=0.33$.

We assume that the discount factor evolves according to a persistent three-state Markov chain pinned down by four conditions: 1) at every point in time the majority of the population (80\%) has $\beta=0.96$, and the very patient and very impatient agents have a mass of $10 \%$ each; 2 ) the average duration of a given discount factor is 50 years, which is meant to capture a dynastic element in this infinite horizon model; 3) agents do not jump over a state; 4) the equidistant difference between the three grid points is calibrated jointly with the borrowing constraint, $\underline{k}$, to be broadly consistent with the fraction of households with negative wealth in U.S. data and the Gini coefficient of the U.S. wealth distribution. This calibration strategy as well as its targets, $11 \%$ for the fraction of negative net wealth holders and 0.79 for the Gini coefficient, is taken from Krusell and Smith (1998) and adapted to the annual frequency. We find that given the above labor income process a small borrowing constraint of 0.01 and the following grid for $\beta$ is broadly consistent with the calibration targets: $[0.94,0.96,0.98]$. Appendix E displays the exact specifications of the three Markov chains for $z, \epsilon$ and $\beta$.

Two parameters remain to be calibrated: $\theta$, the weight on government purchases; and $\chi$, the

exponent of the weighting function in the political aggregation mechanism. For $\theta$ we adopt the following baseline strategy: given the set of parameters above and a value for $\chi$, we choose $\theta$ so 
that the model matches the time-averaged $\frac{G}{Y}$-ratio based on aggregate nondefense government purchases, $G N D$, i.e. roughly $15 \% .{ }^{15}$ We thus follow the empirical literature that views only defense government purchases as a truly exogenous stochastic process and uses this assumption for the identification of the economic consequences of government spending shocks. Of course, since this paper is about endogenous government purchases we simply take the complement, i.e. nondefense government purchases. We check for robustness with respect to this target choice in Section 4.2. For $\chi$ we take no a priori stance and rather vary $\chi$ parametrically. We do, however, argue that the political inequality of our preferred model, is broadly in line with the political participation data in Table 2, Section 2.2.

\section{Results}

\subsection{The Baseline Result}

In this section, we show that decoupling between government purchases and the overall cycle increases with the degree of wealth-bias in the political system, parameterized by the exponent in the political weight function. Starting from the case with no wealth bias in the social welfare function - every agent in the economy has the same political weight - we increase $\chi$ and plot in Figure 3 the contemporaneous correlation coefficient between output and government purchases. We do this for the baseline computation/calibration and three variants: first, we simply leave out the Gini coefficient in the Krusell-Smith rules for capital and government purchases ("No Gini in KS rule" - dashed line), and recompute the equilibrium; secondly, we do not target a realistic Gini coefficient in the simulated wealth distribution and set the discount factor deterministically to its median value of 0.96 , but leave the higher moment in the Krusell-Smith rules (dashed-dotted line); thirdly, we combine both changes (dotted line). ${ }^{16}$

The comovement between output and government purchases declines with the degree of wealth bias in the baseline case. At a value of $\chi=0.55$ the model matches the observed contemporaneous comovement between government purchases and output almost exactly. Comparing the baseline simulation with the Gini coefficient in the Krusell-Smith rules and the recomputed equilibrium without any higher moments reveals a quantitatively realistic example where there is at least a small deviation from approximate aggregation in the sense of Krusell and Smith (1998). Using a measure of wealth inequality in the equilibrium law of motion changes actual equilibrium dynamics slightly for higher political bias parameters - the solid and the

\footnotetext{
${ }^{15}$ Appendix E provides the values of $\theta$ for the different models.

${ }^{16}$ The resulting Gini coefficient is 0.46 and the fraction of negative wealth holders is $2.8 \%$ across models, whether we use the Gini coefficient or not in the Krusell-Smith rules.
} 
Figure 3: Correlation Between $Y$ and $G$ as a Function of Wealth Bias in the Baseline Calibration

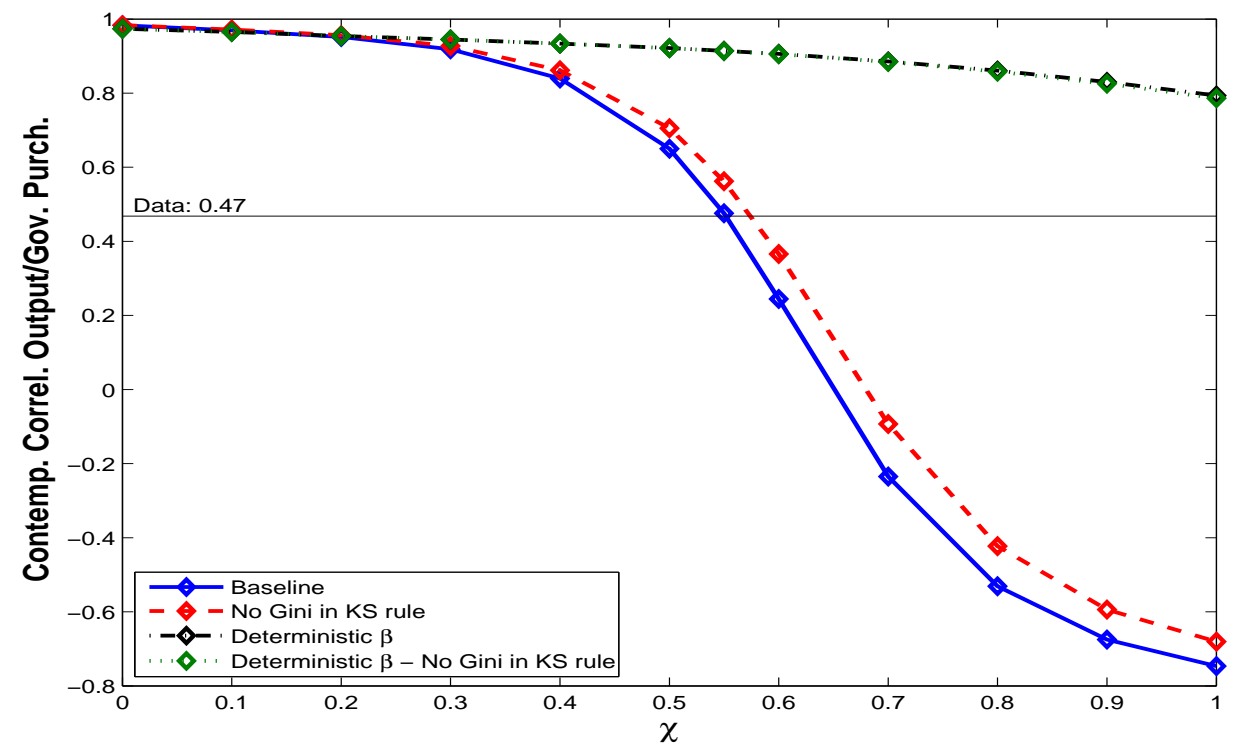

Notes: In the simulations, all variables are logged and filtered with a Hodrick-Prescott filter with smoothing parameter 100. The simulation numbers come from a simulation of 1500 periods, where the first 500 periods were discarded. The simulation is started from an arbitrary initial wealth distribution. All simulations use the same series of aggregate shocks. 'No Gini in KS rule' refers to the equilibrium, when we simply leave out the Gini coefficient in the Krusell-Smith rules for capital and government purchases. 'Deterministic $\beta$ ' refers to the equilibrium, when we make the discount factor deterministic and set it to its median value 0.96 , but continue to use the Gini coefficient in the Krusell-Smith rules for capital and government purchases. 'Deterministic $\beta$ - No Gini in KS rule' refers to the equilibrium with deterministic $\beta$ and no Gini coefficient in the Krusell-Smith rules.

dashed line deviate from each other for higher $\chi$. When agents do not take into account the dynamics of wealth inequality in their forecasting rules, the decoupling effect that a highly unequal wealth distribution in concert with a wealth-biased political system brings about is slightly mitigated. The contemporaneous correlation between output and government purchases increases from 0.48 to 0.56 , when the Gini coefficient is left out. Figure 3 also shows that using a counterfactual wealth distribution with mild economic inequality nearly eliminates the effect of wealth bias on aggregate government purchases dynamics, whether we include higher moments in the forecasting rules or not. Finally, in the case of complete political equality, $\chi=0$, the extent of economic heterogeneity seems irrelevant for aggregate dynamics.

Table 4 , which analyzes the baseline specification with $\chi=0.55$ more closely, shows that when the mildly positive contemporaneous correlation between government purchases and output is matched (data moments are in brackets), then also the contemporaneous correlation between government purchases and private consumption is relatively low, and the same holds true for the correlation between government purchases and lagged output. In particular the two output correlations have the correct relative size. Our model is also consistent with government 
Table 4: BASEline Simulation Results $-\chi=0.55$

\begin{tabular}{lcccc}
\hline \hline Moment & Correl. w. Y & Correl. w. Y-Lag. & Correl. w. C & Autocorrel. 1st-order \\
\hline$Y$ & $1.00(1.00)$ & $0.51(0.54)$ & $0.93(0.87)$ & $0.51(0.54)$ \\
$C$ & $0.93(0.87)$ & $0.69(0.41)$ & $1.00(1.00)$ & $0.65(0.62)$ \\
$I$ & $0.97(0.84)$ & $0.34(0.21)$ & $0.81(0.69)$ & $0.45(0.42)$ \\
$G N D$ & $0.48(0.47)$ & $0.74(0.58)$ & $0.75(0.49)$ & $0.85(0.74)$ \\
$\frac{G N D}{Y}$ & $-0.78(-0.23)$ & $-0.32(0.12)$ & $-0.66(-0.14)$ & $0.75(0.74)$ \\
\hline
\end{tabular}

Notes: see notes to Table 1 and Figure 3. Data moments are in brackets.

purchases being the most persistent component of aggregate demand. ${ }^{17}$ As it is in the data, it is also more persistent than aggregate output. Finally, the model matches at least qualitatively all but one sign of the cyclicality of the $\frac{G}{Y}$-ratio.

Table 5: Simulation Results - The Role of Economic and Political Heterogeneity

\begin{tabular}{lccccc|c}
\hline \hline Moment & $\begin{array}{c}\text { Baseline } \\
(\chi=0.55)\end{array}$ & $\chi=0$ & $\begin{array}{c}\text { Determ. } \beta \\
\chi=0.55\end{array}$ & $\begin{array}{c}\text { Rep. Agent } \\
\text { No Lag }\end{array}$ & $\begin{array}{c}\text { Rep. Agent } \\
\text { Lag }\end{array}$ & Data \\
\hline$G$ & & & & & & \\
\hline Correl. w. Y & 0.48 & 0.99 & 0.92 & 0.97 & 0.43 & 0.47 \\
Correl. w. Y-Lag. & 0.74 & 0.60 & 0.70 & 0.66 & 0.97 & 0.58 \\
Correl. w. C & 0.75 & 0.98 & 1.00 & 0.98 & 0.70 & 0.49 \\
Autocorrel. 1st-order & 0.85 & 0.57 & 0.67 & 0.62 & 0.61 & 0.74 \\
\hline$C$ & & & & & & \\
\hline Correl. w. Y & 0.93 & 0.93 & 0.91 & 0.90 & 0.92 & 0.87 \\
Autocorrel. 1st-order & 0.65 & 0.65 & 0.68 & 0.69 & 0.68 & 0.62 \\
\hline
\end{tabular}

Notes: see notes to table 4. 'Baseline' refers to the heterogeneous agent model with wealth bias parameter $\chi=0.55$. $\chi=0$ is a model without any wealth bias, i.e. political inequality, in the social welfare function. 'Determ. $\beta$ ' refers to a case, when we make the discount factor deterministic and set it to its median value 0.96 , but continue to use the Gini coefficient in the Krusell-Smith rules for capital and government purchases. We essentially keep the same parameter for political inequality as in the baseline case, i.e. $\chi=0.55$, but reduce the extent of wealth inequality. 'Rep. Agent No Lag' refers to a simulation, where we abstract from any heterogeneity, i.e. $\epsilon$ and $\beta$ are held constant, and the political decision is about current government purchases. 'Rep. Agent Lag' refers to a simulation, where where we abstract from any heterogeneity and the political decision about government purchases features a decision lag of one year ahead. All simulations use the same series of aggregate shocks.

Table 5 compares the business cycle moments of government purchases from the baseline specification with those from models that do not generate decoupling. Models with either a lack of realistic economic inequality (independently of the extent of political inequality) - the 'De-

\footnotetext{
${ }^{17}$ The model overshoots, but $G N D$ is one of the least persistent government purchases aggregates. Had we calibrated to $G$, as we do in Section 4.2, we would have matched the high persistence almost perfectly.
} 
term. $\beta$ '-column in the table - or with a lack of political inequality (independently of whether they feature realistic economic inequality) - the $\chi=0$-column in the table - behave in the aggregate essentially like representative agent versions of the model without any heterogeneity and inequality - the 'Rep. Agent No Lag'-column in the table. This finding is valid for other moments and other aggregate variables not shown in Table 5. We thus provide another case of irrelevance of wealth heterogeneity for aggregate dynamics - government purchases dynamics, to be precise -, extending the finding of Krusell and Smith (1998) to a class of models with endogenous public policy. However, once both types of heterogeneity are combined, they matter for the aggregate dynamics of government purchases. Because of this, government purchases dynamics provide important restrictions on a difficult-to-measure structural parameter, namely the wealth bias in the political system, which suggests that future empirical research might benefit from taking these dynamics into account. Only the baseline model with both economic and political inequality generates the right level of procyclicality of government purchases. With a fixed discount factor, economic inequality is too small to matter. While the 'Determ. $\beta$ '-case with lower wealth inequality has a negative relationship between wealth bias and the comovement of GDP and government purchases, the gradient is small. With $\chi=0$, economic inequality does not get translated into political inequality.

Table 5 also shows that the specification with both types of inequality has other important moments closer to the data, in particular the correlation of government purchases with private consumption and the persistence of government purchases. Only in the baseline specification is $G$ the most persistent component of aggregate demand. This is consistent with the fact that government purchases dynamics now depend directly on a slow-moving and itself persistent object, the wealth distribution.

The baseline model is the only one with the right relative size between the contemporaneous and the dynamic correlation of $G$ and GDP. However, this could be an artifact of us not allowing for decision and implementation lags in the political process. In order to test, whether the excess synchronization in the representative agent model is an artifact of abstracting from such lags, we simulated a version of the representative household economy, where the political process decides about next period's government purchases, making current government purchases an additional state variable of the economy. As Table 5 in the 'Rep. Agent Lag'-column shows, this solves the problem of the contemporaneous correlation of government purchases with GDP, now at 0.43 , which is close to the 0.47 in the data. But this comes, perhaps not surprisingly, at the cost of an oversynchronization (relative to the data) with lagged output.

Next, we show in Table 6 that the degree of wealth-bias that is most in line with aggregate government purchases dynamics is also consistent with the average degree of political inequality as measured by the incidence of campaign contributions across the income percentiles in 
the American National Election Studies (ANES). We compare the weight-shares in the social welfare function when $\chi=0.55$ to the campaign contribution shares in the ANES data. It is apparent that the political bias towards high income agents in our model at least broadly lines up with the political bias exhibited in the measured campaign contribution shares. Relative to these, our baseline calibration exhibits slightly larger political inequality. Since these measured campaign contribution shares do not take into account the size of the contributions made by the different income groups, they almost surely understate political inequality.

Table 6: Political Participation Per Income Group - Baseline Simulation - $\chi=0.55$

\begin{tabular}{lccccc}
\hline \hline Income Percentile & {$[0-16 \%]$} & {$[17-33 \%]$} & {$[34-67 \%]$} & {$[68-95 \%]$} & {$[96-100 \%]$} \\
\hline Weight shares - Baseline Model & $2.9 \%$ & $7.2 \%$ & $25.7 \%$ & $41.8 \%$ & $22.4 \%$ \\
Campaign contribution shares & $5.0 \%$ & $8.1 \%$ & $27.5 \%$ & $41.9 \%$ & $17.5 \%$ \\
\hline
\end{tabular}

Notes: 'Weight shares' refers to the (time-averaged) weight shares in the social welfare function for each income percentile. 'Campaign contribution shares' are the average fractions of campaign contributors that belong to a certain percentile of the income distribution. Data source is the American National Election Studies. See Table 2 in Section 2.2.

We finish this section by showing that the decoupling we find in the simulations with sufficient economic and political inequality is caused by a shift of political power for agents over the business cycle. Figure 4 shows that the average desired $G$ increases with wealth and income quintiles. Figure 5 is the analog to Table 3 in Section 2.2. Just like in the American National Election Studies data, the relative political influence of the poor increases in good economic times, whereas the rich lose some of their weight in the political decision process. In good economic times the poor have slightly more say and they want on average lower government purchases, which mitigates the expansion of $G$ in a boom. Figure 5 also shows that only mild procyclicality of the political influence of the poor and mild countercyclicality of the political influence of the rich, consistent with the data, are required to generate the extent of decoupling observed in aggregate government purchases. 
Figure 4: Desired Government Purchases per Wealth/Income Quintile
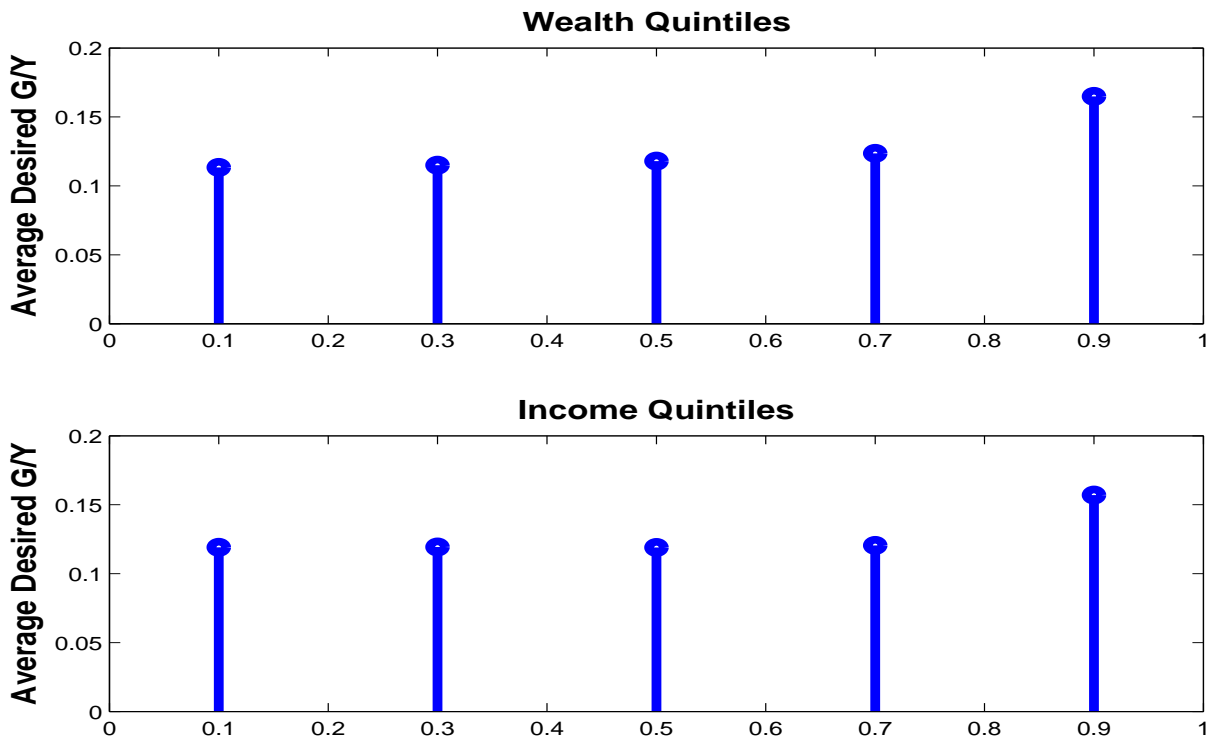

Notes: We use the simulation with $\chi=0.55$ and $\theta=0.815$. We compute for each of the $N_{H}=60,000$ agents at every point in the simulation their desired level of government purchases, using their indirect net present value utility function over government purchases, $J_{i}$. With this we can compute the conditional averages of desired government purchases per wealth or income quintile. We normalize these conditional means by the level of aggregate output at that point in time. The figure plots the time averages of these numbers.

Figure 5: Cyclicality of Political Influence per Wealth/Income Quintile as a Function of the Wealth Bias
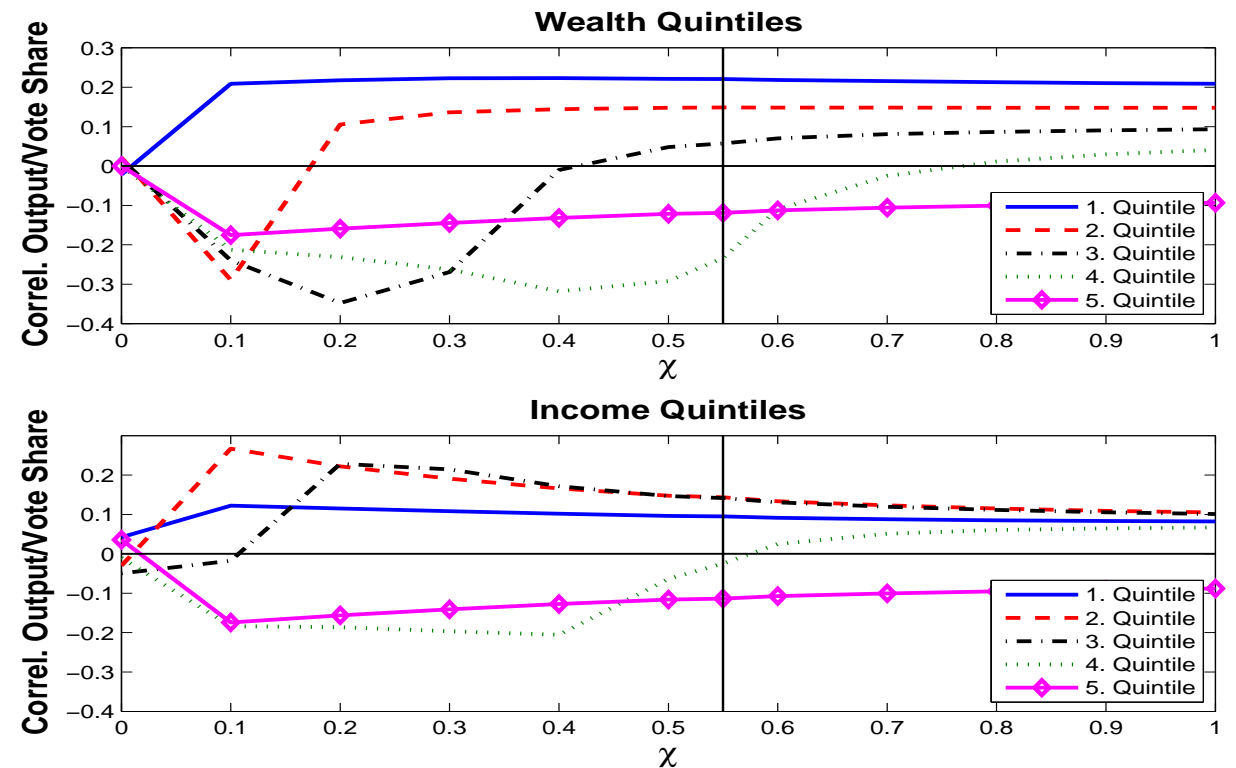

Notes: For every simulation, as $\chi$ varies, we compute the weight shares in the social welfare function for each wealth or income quintile. We then compute for each wealth or income quintile's weight share the contemporaneous correlation coefficients with model simulated output, which is logged and filtered with a Hodrick-Prescott filter with smoothing parameter 100 . 


\subsection{Robustness}

In this section we discuss robustness of our results with respect to one calibration choice and one modeling choice we have made in our baseline case. There we use government nondefense purchases as a proxy for endogenous government purchases. It is not obvious that all defense government spending is orthogonal to the state of the economy. This seems especially plausible for military spending in peace times. In fact, Table 7 in Appendix B suggests that, if anything, federal defense expenditures are somewhat more correlated with the cycle than federal nondefense expenditures.

Figure 6: Correlation Between $Y$ and $G$ as a Function of Wealth Bias - Calibration to Total Government Purchases

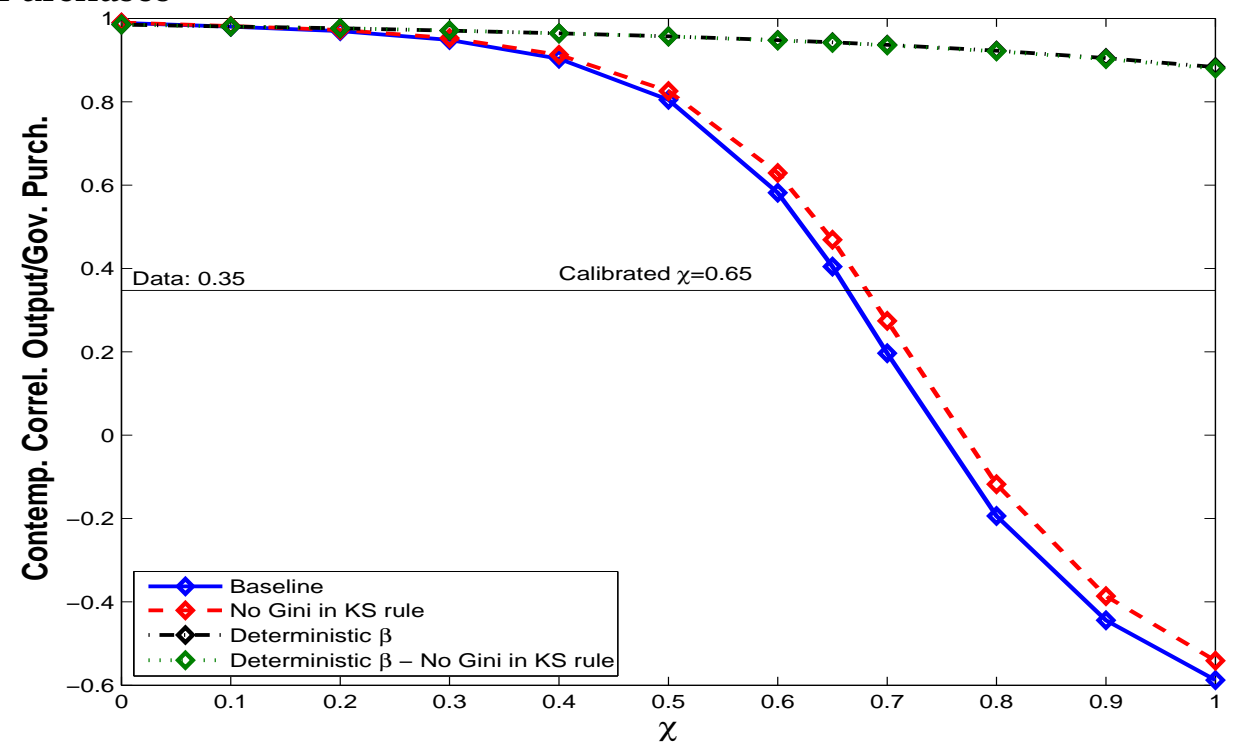

Notes: see notes to figure 3.

Therefore, we repeat our baseline exercise, but calibrate the weight of government purchases, $\theta$, to match the $\frac{G}{Y}$-ratio based on total government consumption and investment expenditures, $G$, including defense spending: 22.5\%. Figure 6 shows the equivalent of Figure 3 in Section 4.2, when we use $G$ as our data counterpart. It can again be seen that higher political bias leads to a decoupling of government purchases and the aggregate economy. For the 'total government purchases'-calibration the contemporaneous correlation between GDP and government purchases is approximately matched at $\chi=0.65$.

Secondly, the baseline model featured a (wealth-weighted) social welfare function as the political aggregation mechanism, which Appendix C shows to be equivalent to a (wealth-weighted) probabilistic voting mechanism. In this section, we study a case where we use (wealth-weighted) majority voting as the political constitution with vote allocation for type $(k, \epsilon, \beta)$ equal to $\left(k^{+}\right)^{\chi}$. 
As in a standard majority voting environment, the policy with fifty percent of the votes will be the winner if the preference of every household is single-peaked. ${ }^{18}$

Specifically, let $\widehat{G}(k, \epsilon, \beta, \Gamma, z ; \Psi, H)=\arg \max _{G} J(k, \epsilon, \beta, \Gamma, z, G ; \Psi, H)$ be the preferred policy of economic type $(k, \epsilon, \beta)$. Then the Cordorcet winner in a weighted majority voting system is the preferred policy of type $\left(k^{*}, \epsilon^{*}, \beta^{*}\right)$ such that

$$
\frac{\int_{\left\{i: \widehat{G}\left(k_{i}, \epsilon_{i}, \beta_{i}\right)<\widehat{G}\left(k^{*}, \epsilon^{*}, \beta^{*}\right)\right\}}\left(k_{i}^{+}\right)^{\chi} d i}{\int\left(k_{i}^{+}\right) \chi d i}=\frac{1}{2} .
$$

Figure 7: Correlation Between $Y$ and $G$ as a Function of Wealth Bias - Wealth-weighted Majority Voting

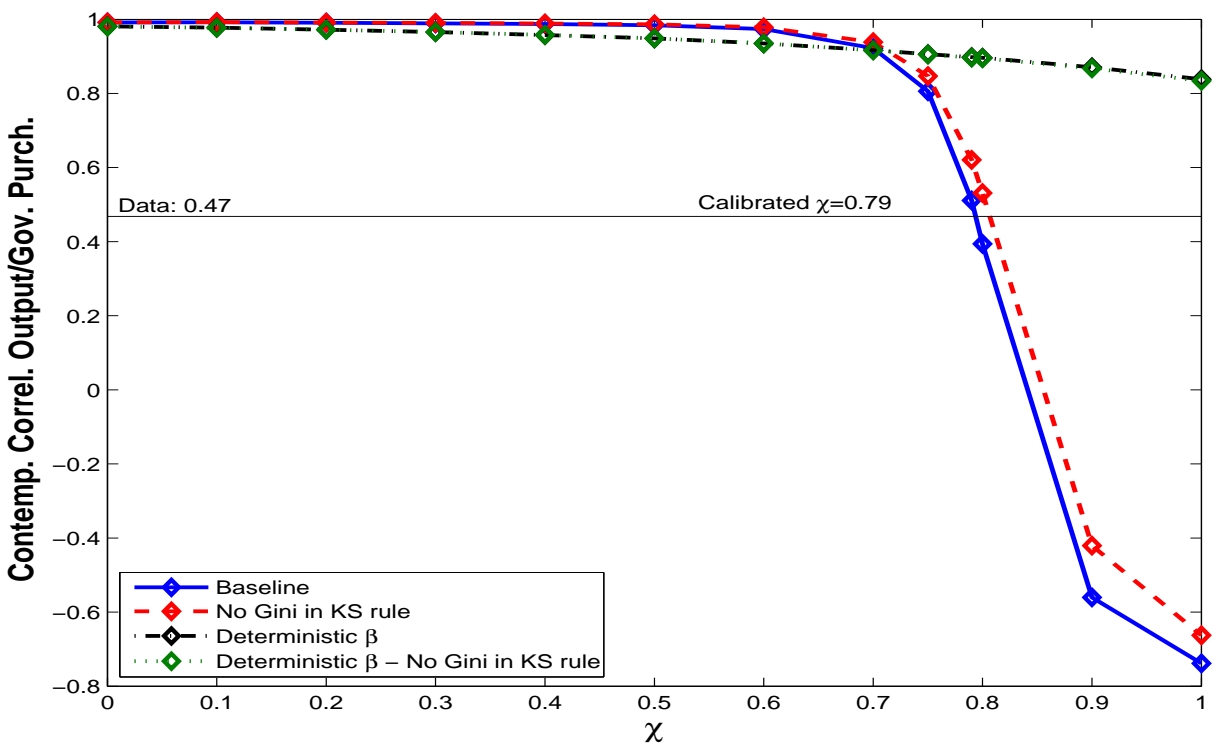

Notes: see notes to figure 3.

Figure 7 repeats our exercises for the case of majority voting, where again higher political bias yields decoupling of government purchases and the aggregate economy. For the majority voting case the slope of the decline of the contemporaneous correlation coefficient between output and government purchases in $\chi$ is much flatter initially and much steeper for higher values of $\chi$, compared to the social welfare function case. The contemporaneous correlation between GDP and government purchases is approximately matched at $\chi=0.79$.

\footnotetext{
${ }^{18}$ In the voting literature, there are different sufficient conditions to guarantee the existence of the voting equilibrium, e.g., single-peakedness, intermediate preference and single crossing (or equivalently order restriction) conditions (see Persson and Tabellini, 2000, for an overview). Although there are general existence results for the complete-market neoclassical growth model with policy commitment(see Bassetto and Benhabib, 2006), we are not aware of similar results applicable to our environment. Nevertheless, we verify numerically that singlepeakedness is satisfied in our simulations.
} 


\section{Final Remarks}

This paper provides a quantitative theory of the implications of economic and political inequality for the business cycle comovement of government purchases. We show that with both types of inequality present in a quantitatively realistic way, the interaction of government purchases being a normal good and countercyclical political inequality can alter the cyclicality of government purchases compared to models where either type of inequality is missing. An extreme case of the latter is a representative agent environment. We argue that in standard models the procyclicality of government purchases may be dampened in the presence of economic and economically-based political inequality. This finding does not depend on the specifics of the political system, nor the average importance of the government sector in the economy. In contrast, standard neoclassical representative agent models of endogenous public policy feature strong procyclicality of government purchases. We thus provide an example of a quantitatively realistic model, where heterogeneity matters for aggregate dynamics, specifically the dynamics of government purchases. We leave it for future research to understand the business cycle dynamics of endogenously determined public policies in Markov-perfect environments more comprehensively. 


\section{References}

[1] Acemoglu, D., M. Golosov, and A. Tsyvinski (2009). "Power Fluctuations and Political Economy", mimeo.

[2] Aguiar, M., and M. Amador (2009). “Growth in the Shadow of Expropriation”, mimeo.

[3] Alesina, A., F. Campante and G. Tabellini (2008). "Why is Fiscal Policy Often Procyclical”, Journal of the European Economic Association, 6, 5, 1006-1036.

[4] Aiyagari, S.R. (1994). "Uninsured Idiosyncratic Risk and Aggregate Saving”, The Quarterly Journal of Economics, 109, 3, 659-684.

[5] Azzimonti, M., (2009). "Barriers to investment in polarized societies”, mimeo.

[6] Azzimonti, M., M. Battaglini and S. Coate (2008). "Analyzing the Case for a Balanced Budget Amendment to the U.S. Constitution", mimeo.

[7] Bai, J.H., and R. Lagunoff (2009). "Revealed Political Power”, Georgetown Working Paper.

[8] Bai, J.H., and R. Lagunoff (2010). “On the Faustian Dynamics of Policy and Political Power”, Review of Economic Studies, forthcoming.

[9] Bartels, L. (2008). "Unequal Democracy: The Political Economy of the New Gilded Age”, Princeton University Press.

[10] Bassetto, M., and J. Benhabib (2006). "Redistribution, Taxes, and the Median Voter", Review of Economic Dynamics, 9 (2), 211-223.

[11] Battaglini, M. (2010). “Dynamic Electoral Competition and Constitutional Design”, mimeo.

[12] Battaglini, M. and S. Coate (2008a). "A Dynamic Theory of Public Spending, Taxation and Debt", American Economic Review, 98 (1), 201-236.

[13] Battaglini, M. and S. Coate (2008b). "Fiscal Policy over the Real Business Cycle: A Positive Theory", mimeo.

[14] Benabou, R. (2000). "Unequal Societies: Income Distribution and the Social Contract", American Economic Review, 90 (1), 96-129.

[15] Campante, F., (2008). "Redistribution in a Model of Voting and Campaign Contributions", mimeo. 
[16] Corbae, D., P. D’Erasmo and B. Kuruscu (2009). "Politico-economic consequences of rising wage inequality", Journal of Monetary Economics, 56, 43-61.

[17] Debortoli, D., and R. Nunes (2010). "Fiscal Policy under Loose Commitment", Journal of Economic Theory, 145/3, 1005-1032.

[18] Diaz-Gimenez, J., V. Quadrini and V. Rios-Rull (1997). "Dimensions of Inequality: Facts on the U.S. Distributions of Earnings, Income, and Wealth”, Federal Reserve Bank of Minneapolis Quarterly Review, 21/2, 3-21.

[19] Farhi, E., and I. Werning (2008). “The Political Economy of Nonlinear Capital Taxation”, mimeo.

[20] Gomes, F., A. Michaelides and V. Polkovnichenko (2008). "Fiscal Policy in an Incomplete Markets Economy", mimeo.

[21] Guvenen, F, and A. Smith (2008). "Inferring Labor Income Risk From Economic Choices: An Indirect Inference Approach”, mimeo.

[22] Hassler, J., J. Mora K. Storesletten and F. Zilibotti (2003). "The Survival of the Welfare State", American Economic Review, 93, 87-112.

[23] Hassler, J., P. Krusell, K. Storesletten and F. Zilibotti (2005). “The Dynamics of Government", Journal of Monetay Economics, 52, 7, 1331-1358.

[24] Heathcote, J. (2005). "Fiscal Policy with Heterogeneous Agents and Incomplete Markets", Review of Economic Studies, 72, 161-188.

[25] Heathcote, J., K. Storesletten and G. Violante (2010). "Unequal We Stand: An Empirical Analysis of Economic Inequality in the United States, 1967-2006", Review of Economic Dynamics, 13/1, 15-51.

[26] Huggett, M. (1993). “The Risk-Free Rate in Heterogeneous-Agent Incomplete-Insurance Economies", Journal of Economic Dynamics and Control, 17, 953-969.

[27] Ilzetzki, E. (2007). “Rent-seeking Distortions and Fiscal Procyclicality”, mimeo.

[28] Ilzetzki, E. and C. Vegh (2008). "Procyclical Fiscal Policy in Developing Countries: Truth or Fiction?", mimeo.

[29] Klein, P., P. Krusell and V. Rios-Rull (2008). “Time-Consistent Public Policy”, Review of Economic Studies, 75, 789-808. 
[30] Krusell, P., V. Quadrini and V. Rios-Rull (1997). "Politico-economic equilibrium and economic growth", Journal of Economic Dynamics and Control, 21 (5), 243-272.

[31] Krusell, P. and V. Rios-Rull (1999). "On the Size of U.S. Government: Political Economy in the Neoclassical Growth Model”, American Economic Review, 98 (5), 1156-1181.

[32] Krusell, P. and A. Smith (1997). "Income and Wealth Heterogeneity, Portfolio Choice and Equilibrium Asset Returns”, Macroeconomic Dynamics 1, 387-422.

[33] Krusell, P. and A. Smith (1998). "Income and Wealth Heterogeneity in the Macroeconomy", Journal of Political Economy, 106 (5), 867-896.

[34] Persson, T. and G. Tabellini (2000). "Political Economics: Explaining Economic Policy", MIT Press.

[35] Rosenstone, S. and J. Hansen (1993). "Mobilization, Participation and Democracy in America”, Macmillan, New York.

[36] Song, Z., K. Storesletten and F. Zilibotti (2007). "Rotten Parents and Disciplined Children: A Politico-Economic Theory of Public Expenditure and Debt", mimeo.

[37] Tauchen, G. (1986). "Finite State Markov-Chain Approximations To Univariate and Vector Autoregressions", Economics Letters, 20, 177-181.

[38] Yared, P. (2010). "Politicians, Taxes and Debt", Reveiw of Economic Studies, 77, 806-840. 


\section{A Proofs - Appendix}

Proof of proposition 1: Substitute the budget constraint (4) for private consumption in (1), use the CRRA assumption, and, suppressing the arguments in $p(k, \epsilon ; K, L)$, take the derivative with respect to $G$ :

$$
F O C(G, z, k) \equiv-\theta p u_{1}^{\prime}\left((1-\delta) k+p z K^{\alpha} L^{1-\alpha}-p G\right)+(1-\theta) u_{2}^{\prime}(G)=0 .
$$

By the implicit function theorem and the strict concavity of the objective function, we need to show that $\frac{\partial F O C(G, z, k)}{\partial z}>0$ and $\frac{\partial F O C(G, z, k)}{\partial k}>0$ to prove the result.

$$
\frac{\partial F O C(G, z, k)}{\partial z}=-\theta p^{2} u_{1}^{\prime}\left((1-\delta) k+p z K^{\alpha} L^{1-\alpha}-p G\right) K^{\alpha} L^{1-\alpha}>0
$$

by strict concavity of $u_{1}$.

For $\frac{\partial F O C(G, z, k)}{\partial k}>0$ we specialize $\operatorname{FOC}(G, z, k)$ to

$$
F O C(G, z, k) \equiv-\theta p\left((1-\delta) k+p z K^{\alpha} L^{1-\alpha}-p G\right)^{\gamma-1}+(1-\theta) u_{2}^{\prime}(G)=0 .
$$

Then:

$$
\begin{gathered}
\frac{\partial F O C(G, z, k)}{\partial k}=-\theta p(\gamma-1)\left((1-\delta) k+p z K^{\alpha} L^{1-\alpha}-p G\right)^{\gamma-2}\left((1-\delta)+\frac{\partial p}{\partial k}\left(z K^{\alpha} L^{1-\alpha}-G\right)\right)- \\
\theta \frac{\partial p}{\partial k}\left((1-\delta) k+p z K^{\alpha} L^{1-\alpha}-p G\right)^{\gamma-1}=-\theta\left((1-\delta) k+p z K^{\alpha} L^{1-\alpha}-p G\right)^{\gamma-2} * \\
{\left[p(\gamma-1)(1-\delta)+\frac{\partial p}{\partial k}\left(p(\gamma-1)\left(z K^{\alpha} L^{1-\alpha}-G\right)+(1-\delta) k+p z K^{\alpha} L^{1-\alpha}-p G\right)\right]=} \\
-\theta\left((1-\delta) k+p z K^{\alpha} L^{1-\alpha}-p G\right)^{\gamma-2}\left[p(\gamma-1)(1-\delta)+\frac{\partial p}{\partial k}\left(p \gamma\left(z K^{\alpha} L^{1-\alpha}-G\right)+(1-\delta) k\right)\right]= \\
-\theta\left((1-\delta) k+p z K^{\alpha} L^{1-\alpha}-p G\right)^{\gamma-2}\left[\left(p-\frac{\partial p}{\partial k} k\right)(\gamma-1)(1-\delta)+\frac{\partial p}{\partial k} \gamma c\right]= \\
-\theta\left((1-\delta) k+p z K^{\alpha} L^{1-\alpha}-p G\right)^{\gamma-2}\left[(1-\alpha) \frac{\tilde{l} \epsilon}{L}(\gamma-1)(1-\delta)+\frac{\partial p}{\partial k} \gamma c\right] .
\end{gathered}
$$

The first factor of the last expression is negative. The second factor is negative for $\gamma \leq 0$ and $\delta \leq 1$ with one inequality holding strict. With linear utility in consumption, $\gamma=1$, $\frac{\partial F O C(G, z, k)}{\partial k}<0$.

Proof of proposition 2: Substituting the budget constraint into the expected utility function, suppressing the arguments of $w(K, L, z), r(K, L, z)$ and $\tau(K, L, z, G)$ as well as their analogs tomorrow, and taking the derivative with respect to $k^{\prime}$, yields: 


$$
\begin{aligned}
& F O C\left(k^{\prime}, w, k\right) \equiv-u_{1}^{\prime}\left((1-\delta) k+(1-\tau)(w \tilde{l} \epsilon+r k)-k^{\prime}\right)+ \\
& \beta E\left[u_{1}^{\prime}\left((1-\delta) k^{\prime}+\left(1-\tau^{\prime}\right)\left(w^{\prime} \tilde{l} \epsilon^{\prime}+r^{\prime} k^{\prime}\right)\right)\left(1-\delta+\left(1-\tau^{\prime}\right) r^{\prime}\right) \mid z, \epsilon\right]=0 .
\end{aligned}
$$

The expectation is taken with respect to $z^{\prime}$ and $\epsilon^{\prime}$. We consider now the effects of an exogenous increase in today's real wage keeping constant tomorrow's factor prices. Specifically, we are interested in how the marginal effect of real wage increases on the saving decision is impacted by individual capital holdings.

First we show that $\frac{\partial F O C\left(k^{\prime}, w, k\right)}{\partial w}>0$, which means, given the concavity of $u_{1}$, that real wage increases lead to higher saving.

$$
\frac{\partial F O C\left(k^{\prime}, w, k\right)}{\partial w}=-u_{1}^{\prime \prime}\left((1-\delta) k+(1-\tau)(w \tilde{l} \epsilon+r k)-k^{\prime}\right)(1-\tau) \tilde{l} \epsilon>0
$$

I.e.:

$(*) \frac{d k^{\prime}}{d w}=$

$\frac{u_{1}^{\prime \prime}\left((1-\delta) k+(1-\tau)(w \tilde{l} \epsilon+r k)-k^{\prime}\right)(1-\tau) \tilde{l} \epsilon}{u_{1}^{\prime \prime}\left((1-\delta) k+(1-\tau)(w \tilde{l} \epsilon+r k)-k^{\prime}\right)+\beta E\left[u_{1}^{\prime \prime}\left((1-\delta) k^{\prime}+\left(1-\tau^{\prime}\right)\left(w^{\prime} \tilde{l} \epsilon^{\prime}+r^{\prime} k^{\prime}\right)\right)\left(1-\delta+\left(1-\tau^{\prime}\right) r^{\prime}\right)^{2} \mid z, \epsilon\right]}>0$.

Next, we look at:

$$
\begin{aligned}
& \frac{d^{2} k^{\prime}}{d w d k}= \\
& \frac{u_{1}^{\prime \prime \prime}(\cdot)(1-\delta+(1-\tau) r)(1-\tau) \tilde{l} \epsilon\left[u_{1}^{\prime \prime}(\cdot)+\beta E\left[u_{1}^{\prime \prime}(\cdot)\left(1-\delta+\left(1-\tau^{\prime}\right) r^{\prime}\right)^{2} \mid z, \epsilon\right]\right]-u_{1}^{\prime \prime}(\cdot)(1-\tau) \tilde{l} \epsilon u_{1}^{\prime \prime \prime}(\cdot)(1-\delta+(1-\tau) r)}{\left[u_{1}^{\prime \prime}\left((1-\delta) k+(1-\tau)(w \tilde{l} \epsilon+r k)-k^{\prime}\right)+\beta E\left[u_{1}^{\prime \prime}\left((1-\delta) k^{\prime}+\left(1-\tau^{\prime}\right)\left(w^{\prime} \tilde{l} \epsilon^{\prime}+r^{\prime} k^{\prime}\right)\right)\left(1-\delta+\left(1-\tau^{\prime}\right) r^{\prime}\right)^{2} \mid z, \epsilon\right]\right]^{2}}
\end{aligned}
$$

Collecting terms, we get:

$$
\begin{aligned}
& \frac{d^{2} k^{\prime}}{d w d k}= \\
& \frac{\left.u_{1}^{\prime \prime \prime}(\cdot)(1-\delta+(1-\tau) r)(1-\tau) \tilde{l} \epsilon \beta E\left[u_{1}^{\prime \prime}(\cdot)\left(1-\delta+\left(1-\tau^{\prime}\right) r^{\prime}\right)^{2} \mid z, \epsilon\right]\right]}{\left[u_{1}^{\prime \prime}\left((1-\delta) k+(1-\tau)(w \tilde{l} \epsilon+r k)-k^{\prime}\right)+\beta E\left[u_{1}^{\prime \prime}\left((1-\delta) k^{\prime}+\left(1-\tau^{\prime}\right)\left(w^{\prime} \tilde{l} \epsilon^{\prime}+r^{\prime} k^{\prime}\right)\right)\left(1-\delta+\left(1-\tau^{\prime}\right) r^{\prime}\right)^{2} \mid z, \epsilon\right]\right]^{2}}<0
\end{aligned}
$$

if $u_{1}(\cdot)^{\prime \prime \prime}>0$. Furthermore, it is easy to show that $\frac{d k^{\prime}}{d k}>0$, which means that, in a group of agents with the same labor productivity, saving as a function of individual capital holdings is increasing, whereas marginal saving with respect to the real wage is decreasing in individual capital holdings. 
Next assume that a group of agents with the same labor productivity is ordered according to their individual capital holdings with ascending order. We are interested in the sign of the following object:

$$
\frac{d \frac{\int_{0}^{i^{*}} k^{\prime}(i) d i}{\int_{0}^{1} k^{\prime}(i) d i}}{d w}
$$

Notice that the expression in the numerator of this derivative is the Lorenz curve of secondperiod capital holdings. We will show that under the stated assumptions and in partial equilibrium the Lorenz curve increases pointwise for each fixed $i^{*}$, and thus inequality decreases in the real wage for a group of agents with the same labor productivity.

$$
\frac{d \frac{\int_{0}^{i^{*}} k^{\prime}(i) d i}{\int_{0}^{1} k^{\prime}(i) d i}}{d w}=\frac{\left[\left(\int_{0}^{i^{*}} \frac{d k^{\prime}(i)}{d w} d i\right)\left(\int_{0}^{1} k^{\prime}(i) d i\right)-\left(\int_{0}^{i^{*}} k^{\prime}(i) d i\right)\left(\int_{0}^{1} \frac{d k^{\prime}(i)}{d w} d i\right)\right]}{\left[\int_{0}^{1} k^{\prime}(i) d i\right]^{2}} .
$$

Splitting up the integrals and rearranging leaves us with:

$$
\frac{d \frac{\int_{0}^{i^{*}} k^{\prime}(i) d i}{\int_{0}^{1} k^{\prime}(i) d i}}{d w}=\frac{\left[\left(\int_{i^{*}}^{1} k^{\prime}(i) d i\right)\left(\int_{0}^{i^{*}} \frac{d k^{\prime}(i)}{d w} d i\right)-\left(\int_{0}^{i^{*}} k^{\prime}(i) d i\right)\left(\int_{i^{*}}^{1} \frac{d k^{\prime}(i)}{d w} d i\right)\right]}{\left[\int_{0}^{1} k^{\prime}(i) d i\right]^{2}}
$$

Given the results from above that saving and marginal saving with respect to the real wage are inversely related in a group of agents with the same labor productivity and the only source of heterogeneity being different individual capital holdings, it is clear that the two factors of the second product are both positive, but smaller than the corresponding factors in the first product. This finishes the proof.

Of course, in general equilibrium, changes in the real wage today could only be brought about by changes in the initial capital stock, the labor endowment, or, most realistically, through a change in aggregate productivity, which would then - through the aggregation of the saving decisions - change tomorrow's aggregate capital holdings and thus factor prices. We ignore these general equilibrium effects here, only then do we get clear analytical results.

But even a more general partial equilibrium statement with respect to a proportional exogenous increase in both the real wage and the real interest rate ignoring aggregate saving is not possible. The reason for this can be seen by analogy from $(*)$, where for $\frac{d k^{\prime}}{d r}$ the numerator would read: $u_{1}^{\prime \prime}\left((1-\delta) k+(1-\tau)(w \tilde{l} \epsilon+r k)-k^{\prime}\right)(1-\tau) k$. Then the cross derivative $\frac{d^{2} k^{\prime}}{d r d k}$ would feature an additional term, where the (negative) second derivative of the utility function multiplies the (negative) denominator in $(*)$. This means that the total effect cannot be signed, even in a simple two-period model. And this, in turn, justifies our use of numerical techniques. 


\section{B Data - Appendix}

Figure 8: Cyclicality of Government Purchases By State

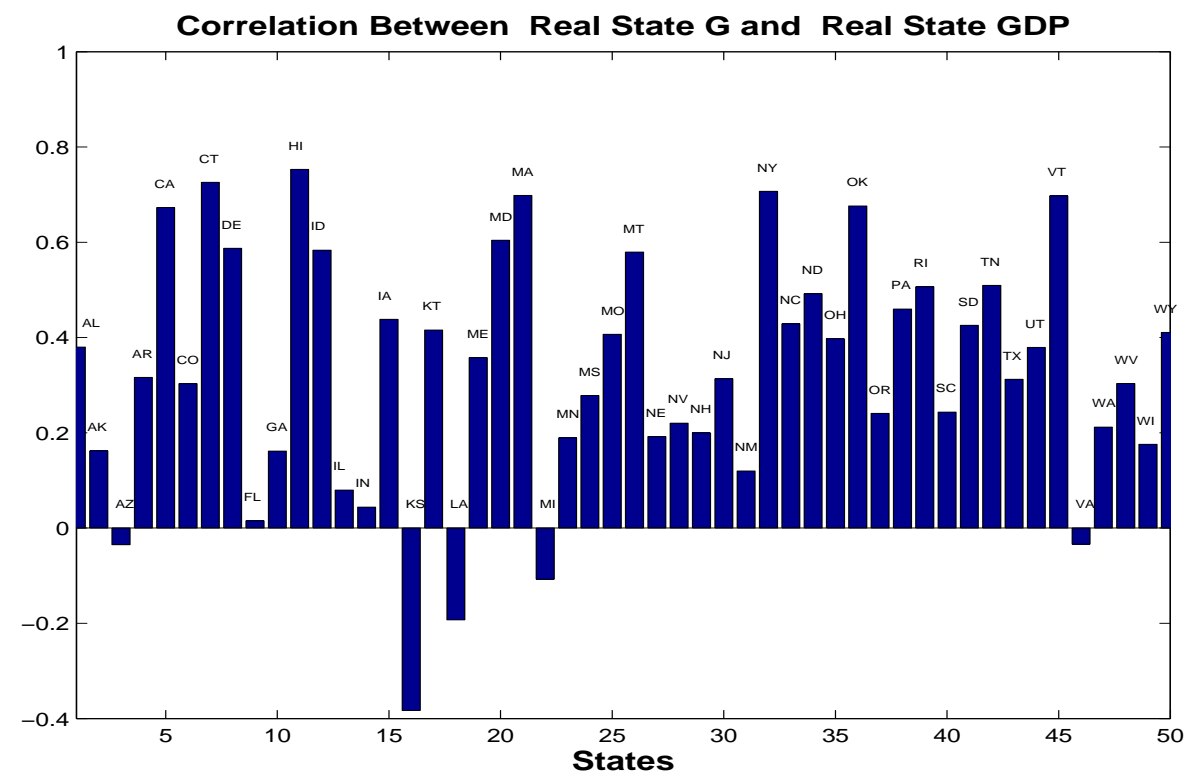

Notes: 'Real State G' is real GDP from the total government sector in the regional NIPA data. 'Real State GDP per capita' is real GDP from the regional NIPA data. All data are logged and filtered with a Hodrick-Prescott filter with smoothing parameter 100.

Figure 9: Relation between the Contemporaneous and the Dynamic Correlation Between $Y$ and $G$ By State

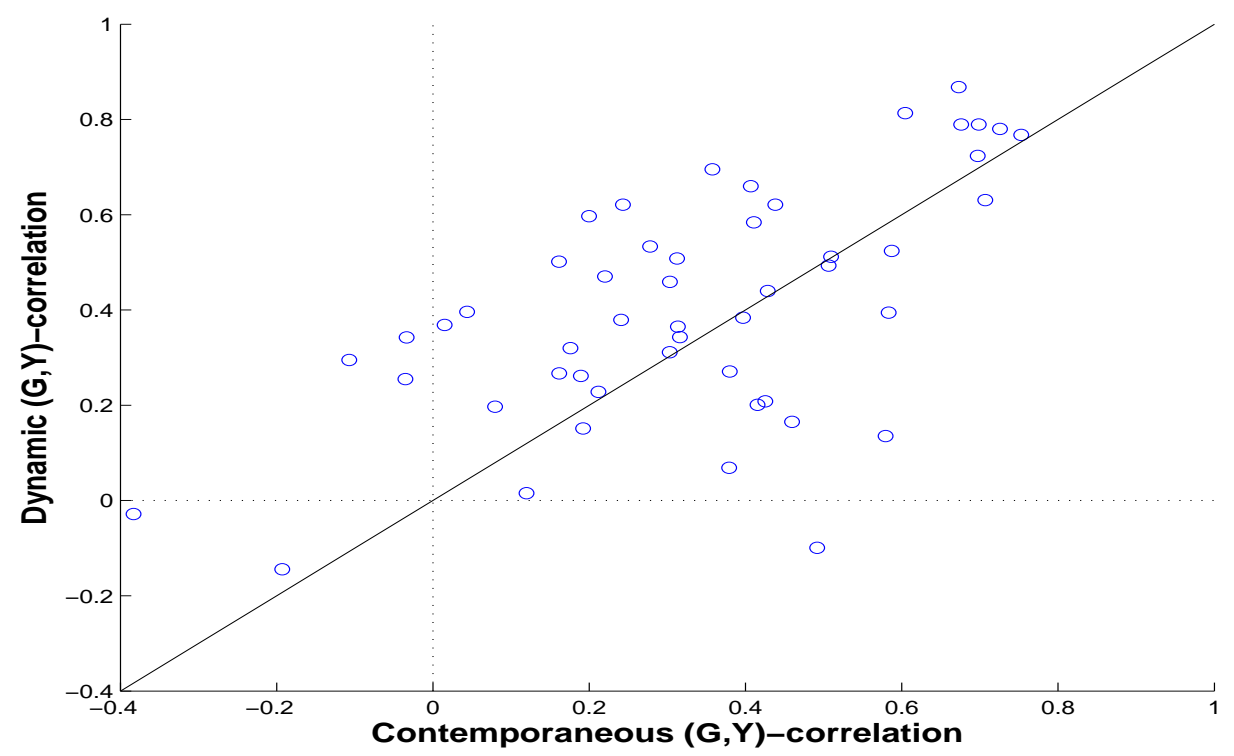

Notes: see notes to Figure 8. 
Table 7: Business CyCle FACTS For Disaggregate Government PurChases

\begin{tabular}{lcccc|r}
\hline \hline Moment & Correl. w. Y & Correl. w. Y-Lag. & Correl. w. C & $\begin{array}{c}\text { Autocorrel. } \\
\text { 1st-order }\end{array}$ & Frac. of G \\
\hline$G$ & & & & 0.79 & $100.0 \%$ \\
$G C$ & 0.35 & 0.51 & 0.35 & 0.78 & $84.6 \%$ \\
$G I$ & 0.26 & 0.43 & 0.30 & 0.75 & $15.6 \%$ \\
$G N D$ & 0.47 & 0.59 & 0.39 & 0.74 & $68.8 \%$ \\
$G N D C$ & 0.48 & 0.58 & 0.49 & 0.70 & $56.5 \%$ \\
$G N D I$ & 0.19 & 0.34 & 0.38 & 0.74 & $12.0 \%$ \\
$G F$ & 0.60 & 0.66 & 0.47 & 0.82 & $42.7 \%$ \\
$G F C$ & 0.15 & 0.27 & 0.11 & 0.82 & $38.3 \%$ \\
$G F I$ & 0.12 & 0.25 & 0.09 & 0.73 & $5.0 \%$ \\
$G F D$ & 0.18 & 0.28 & 0.10 & 0.83 & $31.2 \%$ \\
$G F D C$ & 0.13 & 0.26 & 0.13 & 0.85 & $28.0 \%$ \\
$G F D I$ & 0.13 & 0.24 & 0.12 & 0.71 & $3.6 \%$ \\
$G F N D$ & 0.08 & 0.27 & 0.05 & 0.63 & $11.7 \%$ \\
$G F N D C$ & 0.04 & -0.01 & -0.12 & 0.47 & $10.3 \%$ \\
$G F N D I$ & -0.09 & -0.04 & -0.20 & 0.71 & $1.5 \%$ \\
$G S L$ & 0.27 & 0.03 & 0.06 & 0.76 & $57.1 \%$ \\
$G S L C$ & 0.49 & 0.65 & 0.59 & 0.77 & $46.3 \%$ \\
$G S L I$ & 0.24 & 0.39 & 0.48 & 0.72 & $10.7 \%$ \\
$G S$ & 0.62 & 0.73 & 0.52 & 0.72 & $18.4 \%$ \\
$G S C$ & 0.40 & 0.65 & 0.47 & 0.73 & $14.0 \%$ \\
$G S I$ & 0.10 & 0.41 & 0.27 & 0.69 & $4.2 \%$ \\
$G L$ & 0.57 & 0.62 & 0.55 & 0.70 & $38.7 \%$ \\
$G L C$ & 0.49 & 0.58 & 0.58 & 0.70 & $32.2 \%$ \\
$G L I$ & 0.27 & 0.30 & 0.51 & 0.75 & $6.5 \%$ \\
\hline$G-E m p l$. & 0.26 & 0.62 & 0.20 & & - \\
\hline
\end{tabular}

Notes: $G$ denotes government consumption and gross investment expenditures, a $C$ in an acronym means consumption, an $I$ investment. $D$ stands for defense spending, $N D$ for nondefense. $F$ means federal government, $S L$ the aggregate of state and local governments. $S$ stands for the state level and $L$ for the local level. G-Empl. means government employment. All variables are annual, they range from 1960-2006. Categories G until GSLI are deflated by their corresponding deflators. For the separate state and local level data NIPA does not publish separate price indices. We therefore use the aggregate state and local price deflator for $G S$ and $G L$, and the consumptionand investment-specific aggregate state and local price deflator for GSC/GLC and GSI/GLI, respectively. For columns 2-5 all data are logged and filtered with a Hodrick-Prescott filter with smoothing parameter 100. The last column shows the fraction of each component of government purchases in total G. Sources: Tables 3.9.4 and 3.9.5 from the NIPA accounts for G until GSLI. The separate data for the state and local level come from Tables 3.20 and 3.21 from the NIPA accounts. Government employment data are from the BLS. 
Table 8: Business Cycle Facts for Disaggregate Government Purchases - According TO FUNCTION

\begin{tabular}{|c|c|c|c|c|c|}
\hline Moment & Correl. w. Y & Correl. w. Y-Lag. & Correl. w. C & $\begin{array}{c}\text { Autocorrel. } \\
\text { 1st-order }\end{array}$ & Frac. of $\mathrm{G}$ \\
\hline General public service & 0.10 & 0.17 & 0.38 & 0.69 & $8.3 \%$ \\
\hline National defense & 0.12 & 0.26 & 0.13 & 0.83 & $29.8 \%$ \\
\hline Public order and safety & 0.05 & 0.33 & 0.21 & 0.56 & $9.1 \%$ \\
\hline Economic affairs & 0.37 & 0.35 & 0.22 & 0.72 & $16.4 \%$ \\
\hline Transportation & 0.51 & 0.49 & 0.50 & 0.66 & $10.0 \%$ \\
\hline Space & 0.15 & 0.07 & -0.06 & 0.83 & $1.1 \%$ \\
\hline Other economic affairs & 0.00 & 0.10 & -0.08 & 0.28 & $5.2 \%$ \\
\hline Housing and comm. serv. & 0.22 & 0.47 & 0.13 & 0.41 & $2.3 \%$ \\
\hline Health & -0.29 & -0.03 & -0.19 & 0.76 & $4.5 \%$ \\
\hline Recreation and culture & 0.03 & 0.37 & 0.19 & 0.61 & $1.4 \%$ \\
\hline Education & 0.51 & 0.58 & 0.58 & 0.79 & $25.5 \%$ \\
\hline Income security & 0.04 & 0.13 & 0.04 & 0.45 & $2.9 \%$ \\
\hline F-General public service & -0.25 & -0.10 & -0.12 & 0.54 & $2.1 \%$ \\
\hline F-National defense & 0.12 & 0.26 & 0.13 & 0.83 & $29.8 \%$ \\
\hline F-Public order and safety & 0.06 & -0.15 & 0.17 & 0.41 & $0.9 \%$ \\
\hline F-Economic affairs & 0.11 & 0.03 & -0.10 & 0.61 & $5.0 \%$ \\
\hline F-Transportation & -0.20 & -0.21 & -0.15 & 0.42 & $1.2 \%$ \\
\hline F-Space & 0.15 & 0.07 & -0.06 & 0.83 & $1.1 \%$ \\
\hline F-Other economic affairs & -0.10 & -0.06 & -0.15 & 0.17 & $2.7 \%$ \\
\hline F-Health & -0.04 & -0.05 & 0.04 & 0.33 & $2.4 \%$ \\
\hline F-Recreation and culture & 0.06 & 0.17 & 0.03 & 0.39 & $0.2 \%$ \\
\hline F-Education & 0.17 & 0.09 & 0.11 & 0.31 & $0.3 \%$ \\
\hline F-Income security & -0.09 & -0.04 & -0.29 & 0.29 & $0.6 \%$ \\
\hline SL-General public service & 0.26 & 0.28 & 0.52 & 0.68 & $6.3 \%$ \\
\hline SL-Public order and safety & 0.08 & 0.40 & 0.22 & 0.51 & $8.2 \%$ \\
\hline SL-Economic affairs & 0.54 & 0.58 & 0.49 & 0.70 & $11.4 \%$ \\
\hline SL-Transportation & 0.56 & 0.55 & 0.55 & 0.68 & $8.9 \%$ \\
\hline SL-Other economic affairs & 0.32 & 0.53 & 0.21 & 0.54 & $2.5 \%$ \\
\hline SL-Housing and comm. serv. & 0.26 & 0.50 & 0.16 & 0.41 & $2.2 \%$ \\
\hline SL-Health & -0.30 & -0.01 & -0.27 & 0.70 & $2.1 \%$ \\
\hline SL-Recreation and culture & 0.05 & 0.45 & 0.21 & 0.55 & $01.2 \%$ \\
\hline SL-Education & 0.50 & 0.58 & 0.58 & 0.80 & $25.2 \%$ \\
\hline SL-Elementary and second. & 0.49 & 0.53 & 0.56 & 0.78 & $20.5 \%$ \\
\hline SL-Higher & 0.46 & 0.54 & 0.49 & 0.63 & $3.9 \%$ \\
\hline SL-Libraries and other & 0.35 & 0.55 & 0.45 & 0.65 & $1.0 \%$ \\
\hline SL-Income security & 0.09 & 0.16 & 0.33 & 0.70 & $2.3 \%$ \\
\hline
\end{tabular}

Notes: see notes to Table 7. All variables are deflated by their corresponding deflators. Sources: Tables 3.15 .4 and 3.15.5 from the NIPA accounts. 
Figure 10: The Correlation Between States' GDP Per Capita and Government Purchases - Variant 1
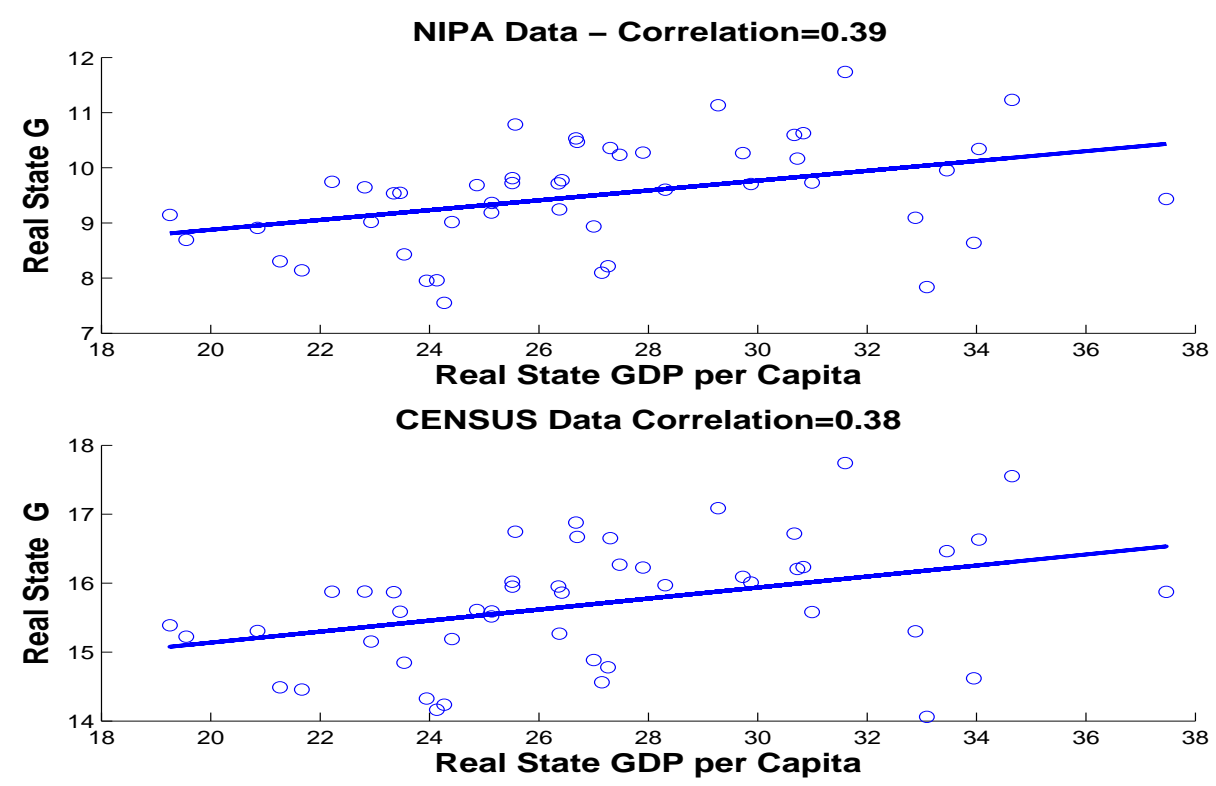

Notes: 'Real State G' in the upper panel is real GDP from the total government sector in the regional NIPA data. 'Real State G' in the lower panel is the sum of the expenditures on 'Total Current Operations' and 'Total Capital Outlays' from the historical data of the census of state government finances, deflated by the state-specific implicit deflator for government GDP from the NIPA data. 'Real State GDP per capita' is real GDP from the regional NIPA data. All data are averaged across time. We present scatter plots of the raw data, excluding the outliers Alaska and Delaware. 
Figure 11: The Correlation Between States' GDP Per Capita and Government Purchases - Variant 2
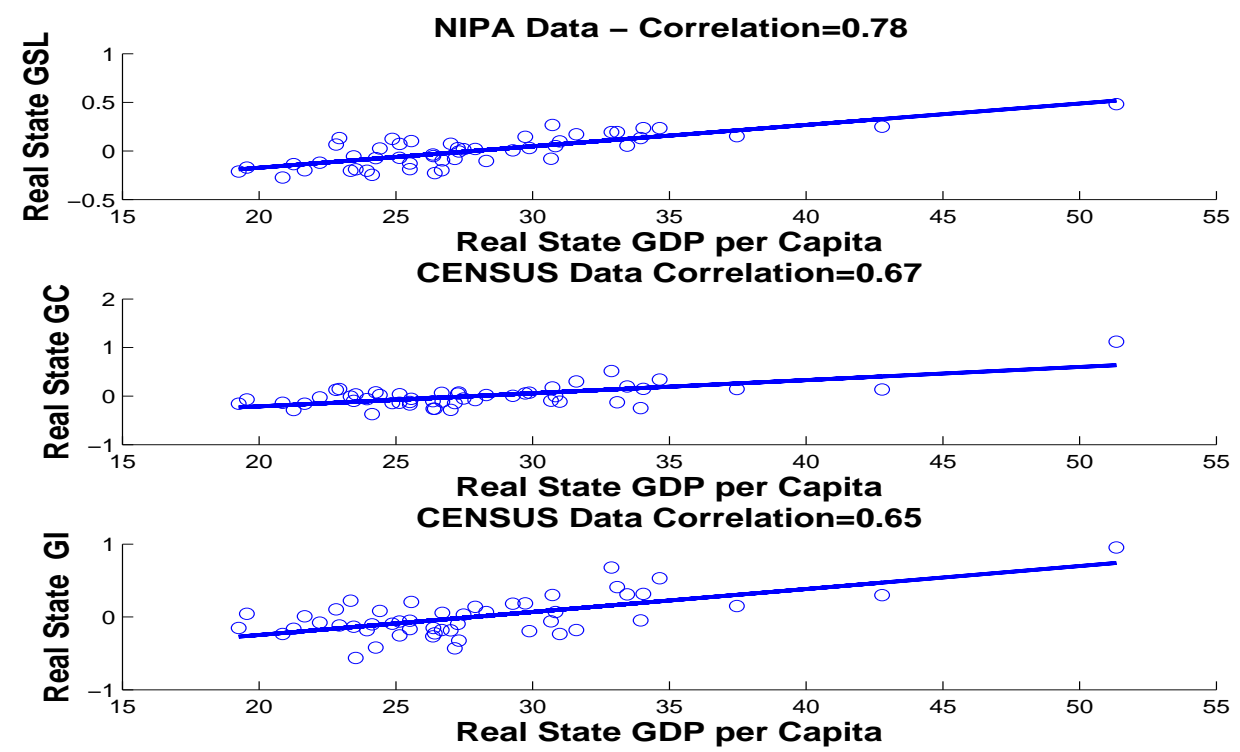

Notes: 'Real State GSL' in the upper panel is real GDP from the state and local government sector in the regional NIPA data. 'Real State GC' in the middle panel is 'Total Current Operations' from the historical data of the census of state government finances, deflated by the state-specific implicit deflator for government GDP from the NIPA data. 'Real State GI' in the lower panel is 'Total Capital Outlays' from the historical data of the census of state government finances, deflated by the state-specific implicit deflator for government GDP from the NIPA data. There are no state-specific deflators for consumption and investment expenditures separately. 'Real State GDP per capita' is real GDP from the regional NIPA data. All data are averaged across time. These averaged 'Real State G' data are regressed on the state's total surface and population. The residuals of these regressions are displayed against 'Real State GDP per capita'. 


\section{A Probabilistic Voting Interpretation - Appendix}

As in the standard probabilistic voting environment, there are two political candidates competing for office. Both candidate A and B are office-seeking with the only objective to maximize their probability of winning. The politicians live for one period and hence are static decision makers. But they have to take into account the dynamic utility of the voters to maximize their winning probability.

Following Lindbeck and Weibull (1987), we introduce an idiosyncratic, $\sigma$, and an aggregate, $d$, element of uncertainty in the political dimension. Both $\sigma$ and $d$ are uniformly distributed random variables and i.i.d. across time, with support $\sigma \in\left[-\frac{1}{2 \phi_{\sigma}}, \frac{1}{2 \phi_{\sigma}}\right]$ and $d \in\left[-\frac{1}{2 \phi_{d}}, \frac{1}{2 \phi_{d}}\right] \cdot{ }^{19} \sigma$ and $d$ represent the political advantage of candidate $\mathrm{B}$ relative to candidate A. With this new political dimension every voter $i j$ is identified by $\left(k_{i}, \epsilon_{i}, \beta_{i}, \sigma_{j}\right)$. More specifically, $\sigma_{j}$ can be interpreted as the realized idiosyncratic "ideology" advantage parameter, for example utility towards issues like abortion, same-sex marriage, etc. $d$ is interpreted as the aggregate "popularity" parameter, for example personal charisma, etc. Both $\sigma$ and $d$ are known to the voters, but they are not known to the politicians. Since $\sigma$ is a purely idiosyncratic component, it does not introduce any de facto uncertainty from the point of view of candidates. But $d$ presents true uncertainty for political candidates, which is a crucial mechanism in a probabilistic voting model.

The felicity function of household $i j$ under policy of the candidate B $\left(G_{B}\right)$ is assumed to be

$$
U\left(c_{i}, G_{B}\right)+\sigma_{j}+d
$$

Taking expectations over future felicity streams and using the iid nature of $\sigma$ and $d$, yields the following best-response value function:

$$
J\left(k_{i}, \epsilon_{i}, \beta_{i}, \Gamma, z, G_{B} ; \Psi, H\right)+\sigma_{j}+d
$$

Under candidate A this is given by $J\left(k_{i}, \epsilon_{i}, \beta_{i}, \Gamma, z, G_{A} ; \Psi, H\right)$. Given any value of $d$ (which is unknown to the candidate), the "swing voter" within an economic type $\left(k_{i}, \epsilon_{i}, \beta_{i}\right)$ is associated with an ideology threshold, $\hat{\sigma}_{i}$, such that

$$
\hat{\sigma}_{i}\left(k_{i}, \epsilon_{i}, \beta_{i}, \Gamma, z, G_{A}, G_{B} ; \Psi, H\right)=J_{i}^{A}-J_{i}{ }^{B}-d,
$$

where $J_{i}{ }^{s}=J_{i}\left(k_{i}, \epsilon_{i}, \beta_{i}, \Gamma, z, G_{s} ; \Psi, H\right), s \in\{A, B\}$. Any political type within economic type $\left(k_{i}, \epsilon_{i}, \beta_{i}\right)$ with $\sigma_{j}<\hat{\sigma}_{i}$ will vote for policy $G_{A}$ and vice versa. As a result, the vote share for candidate A

\footnotetext{
${ }^{19}$ The i.i.d. assumption simplifies the analysis. For a general characterization of dynamic probabilistic voting models with persistent shocks, see Battaglini (2010).
} 
from economic type $\left(k_{i}, \epsilon_{i}, \beta_{i}\right)$ is $\phi_{\sigma} \cdot\left(J_{i}{ }^{A}-J_{i}{ }^{B}-d\right)+\frac{1}{2}$.

Let $\lambda\left(k_{i}\right)=\left(k_{i}^{+}\right)^{\chi}$ denote the number of votes allocated to each member of economic group $\left(k_{i}, \epsilon_{i}, \beta_{i}\right)$. In a standard one-person-one-vote system, $\lambda\left(k_{i}\right)=1$. In a one-dollar-one-vote system, $\lambda\left(k_{i}\right)=k_{i}^{+}$.

The total vote share for policy $G_{A}$ for a given popularity $d$ is therefore

$$
\pi_{A}(d)=\frac{\phi_{\sigma} \int_{0}^{1}\left(k_{i}^{+}\right)^{\chi}\left(J_{i}{ }^{A}-J_{i}{ }^{B}\right) d i}{\int_{0}^{1}\left(k_{i}^{+}\right) \chi d i}-\phi_{\sigma} d+\frac{1}{2} .
$$

The expected winning probability (given the uncertainty from $d$ ) is therefore

$$
\begin{aligned}
& \operatorname{Pr}\left(\pi_{A}(d)>\frac{1}{2}\right) \\
= & \operatorname{Pr}\left(\frac{\int_{0}^{1}\left(k_{i}^{+}\right)^{\chi}\left(J_{i}{ }^{A}-J_{i}{ }^{B}\right) d i}{\int_{0}^{1}\left(k_{i}^{+}\right) \chi d i}>d\right) \\
= & \frac{\phi_{d}}{\int_{0}^{1}\left(k_{i}^{+}\right) \chi d i} \int_{0}^{1}\left(k_{i}^{+}\right)^{\chi}\left(J_{i}{ }^{A}-J_{i}{ }^{B}\right) d i+\frac{1}{2} .
\end{aligned}
$$

Because of the separability of $J_{i}{ }^{A}$ and $J_{i}{ }^{B}$, for any $G_{B}$, a dominant strategy for candidate $A$ is to maximize

$$
\int_{0}^{1}\left(k_{i}^{+}\right)^{\chi} J_{i}^{A} d i
$$

i.e., a utilitarian social welfare function with weighting parameters $\left(k_{i}^{+}\right)^{\chi}$. By symmetry, type $B$ maximizes the same social welfare function. Consequently, both candidates will share the same objective and propose the same policy. 


\section{Computational Algorithm - Appendix}

\section{Algorithm 3 Fixed Point Iteration on $(H, \Psi)$}

Step 0: Select a set of summary statistics of the wealth distribution (K, Gini $(k))$ and fix the functional form. Start from an initial guess of coefficients $\left\{a_{0}^{0}, \ldots, a_{4}^{0}\right\},\left\{\widetilde{a}_{0}^{0}, \ldots, \widetilde{a}_{4}^{0}\right\},\left\{b_{0}^{0}, \ldots, b_{2}^{0}\right\}$ to get initial conjectured functions $\left(H^{0}, \Psi^{0}\right)$. Set up a convergence criterion $\varepsilon$.

Step 1: In step $n$, imposing $\left(H^{n}, \Psi^{n}\right)$ in the best-response optimization problem, use value function iteration to solve for the household's parametric dynamic programming problem. Get the continuation value function $v^{n}\left(k, \epsilon, \beta, \Gamma, z ; \Psi^{n}, H^{n}\right)$.

Step 2: Without imposing $\Psi^{n}$ and instead varying $G$ freely on a finite grid, use $H^{n}$ and $v^{n}\left(k, \epsilon, \beta, \Gamma, z ; \Psi^{n}, H^{n}\right)$ to solve for the best-response value function $J^{n}\left(k, \epsilon, \beta, \Gamma, z, G ; \Psi^{n}, H^{n}\right)$ and decision rule $h^{n}\left(k, \epsilon, \beta, \Gamma, z, G ; \Psi^{n}, H^{n}\right)$.

Step 3: Simulate the economy using $N_{H}$ households and $T$ periods. In each period $t$ of the simulation, calculate the equilibrium policy $G_{t}^{e q .}$ using $J^{n}\left(k, \epsilon, \beta, \Gamma, z, G ; \Psi^{n}, H^{n}\right)$ and the social choice rule. Calculate the best response decision based on $h^{n}\left(k, \epsilon, \beta, \Gamma, z, G ; \Psi^{n}, H^{n}\right)$ for both equilibrium $G_{t}^{e q .}$ and pre-specified $N_{G}$ grid points of $G,\left(G_{t, i}\right)_{i=1}^{N_{G}}$. Gather a time series of $\left(K_{t+1}^{e q .},\left(K_{t+1, i}\right)_{i=1}^{N_{G}}, G i n i_{t+1}^{e q .},\left(G i n i_{t+1, i}\right)_{i=1}^{N_{G}}, G_{t}^{e q .},\left(G_{t, i}\right)_{i=1}^{N_{G}}\right)_{t=1}^{T}$, i.e. capital statistics both on $\left(K_{t+1}^{e q .}\right)$ and off-equilibrium path $\left(\left(K_{t+1, i}\right)_{i=1}^{N_{G}}\right)$, with a total sample size of $T\left(1+N_{G}\right)$.

Step 4: Use gathered time series to get-separately for each value of the z-grid-OLS estimates of $\left\{\widehat{a}_{0}^{n}, \ldots, \widehat{a}_{4}^{n}\right\},\left\{\widehat{\widetilde{a}}_{0}^{n}, \ldots, \widehat{\widetilde{a}}_{4}^{n}\right\},\left\{\widehat{b}_{0}^{n}, \ldots, \widehat{b}_{2}^{n}\right\}$, which with a slight abuse of notation we summarize as $\left(\widehat{H}^{n}, \widehat{\Psi}^{n}\right)$. Notice that obviously $\widehat{H}^{n}$ is updated on both the on-and off-equilibrium paths, $\widehat{\Psi}^{n}$ only on the on-equilibrium path.

Step 5: If $\left|H^{n}-\widehat{H}^{n}\right|<\varepsilon$ and $\left|\Psi^{n}-\widehat{\Psi}^{n}\right|<\varepsilon$, stop. Otherwise, set

$$
\begin{aligned}
H^{n+1} & =\alpha_{H} \times \widehat{H}^{n}+\left(1-\alpha_{H}\right) \times H^{n}, \\
\Psi^{n+1} & =\alpha_{\Psi} \times \widehat{\Psi}^{n}+\left(1-\alpha_{\Psi}\right) \times \Psi^{n},
\end{aligned}
$$

with $\alpha_{H}, \alpha_{\Psi} \in(0,1]$, and go to step 1 .

Step 6: Check whether the R2 of the final OLS regressions are high enough to convey confidence that the true equilibrium rule is well approximated. Otherwise go to step $0 .{ }^{20}$.

\footnotetext{
${ }^{20}$ We chose $\varepsilon=10^{-4}, N_{H}=60,000, T=1,500$, of which we discard the first 500, when we update the KS-rules or compute summary statistics. Following Krusell and Smith (1998), we also make sure that these 60,000 agents are always distributed according to the stationary distributions of the Markov chains that govern $\epsilon$ and $\beta$, and thus avoid introducing artificial aggregate uncertainty owing to the small deviation from the law of large numbers. To eliminate sampling error, we use the same series of aggregate shocks for all iterations and all model simulations.
} 


\section{E Calibration - Appendix}

Table 9: COMMON PARAMETERS

\begin{tabular}{cccc}
\hline Parameter & $\delta$ & $\alpha$ & $\underline{k}$ \\
\hline Value & 0.1 & 0.36 & -0.01 \\
\hline
\end{tabular}

Table 10: Markov Chain: Aggregate Productivity

\begin{tabular}{cccccc}
\hline \hline State & $z_{1}$ & $z_{2}$ & $z_{3}$ & $z_{4}$ & $z_{5}$ \\
Value & 0.9182 & 0.9582 & 1 & 1.0436 & 1.0891 \\
\hline$z_{1}$ & 0.6306 & 0.3676 & 0.0018 & 0.0000 & 0.0000 \\
$z_{2}$ & 0.0382 & 0.7538 & 0.2077 & 0.0003 & 0.0000 \\
$z_{3}$ & 0.0001 & 0.0980 & 0.8039 & 0.0980 & 0.0001 \\
$z_{4}$ & 0.0000 & 0.0003 & 0.2077 & 0.7538 & 0.0382 \\
$z_{5}$ & 0.0000 & 0.0000 & 0.0018 & 0.3676 & 0.6306 \\
\hline
\end{tabular}

Notes: This Markov chain is based on an autocorrelation coefficient of 0.8145 and conditional standard deviation of 0.0165. It was generated with Tauchen's (see Tauchen, 1986) discretization method and a width-parameter of 3. 
Table 11: MARKov CHAin: IDIOSYNCRATIC LABOR ProduCTIVITY

\begin{tabular}{cccccccccc}
\hline \hline State & $\epsilon_{1}$ & $\epsilon_{2}$ & $\epsilon_{3}$ & $\epsilon_{4}$ & $\epsilon_{5}$ & $\epsilon_{6}$ & $\epsilon_{7}$ & $\epsilon_{8}$ & $\epsilon_{9}$ \\
Value & 0.4420 & 0.5421 & 0.6648 & 0.8154 & 1 & 1.2264 & 1.5041 & 1.8447 & 2.2623 \\
\hline$\epsilon_{1}$ & 0.2854 & 0.4292 & 0.2409 & 0.0422 & 0.0023 & 0.0000 & 0.0000 & 0.0000 & 0.0000 \\
$\epsilon_{2}$ & 0.0782 & 0.3102 & 0.4140 & 0.1739 & 0.0227 & 0.0009 & 0.0000 & 0.0000 & 0.0000 \\
$\epsilon_{3}$ & 0.0117 & 0.1167 & 0.3716 & 0.3716 & 0.1167 & 0.0113 & 0.0003 & 0.0000 & 0.0000 \\
$\epsilon_{4}$ & 0.0009 & 0.0227 & 0.1739 & 0.4140 & 0.3102 & 0.0728 & 0.0053 & 0.0001 & 0.0000 \\
$\epsilon_{5}$ & 0.0000 & 0.0023 & 0.0422 & 0.2409 & 0.4292 & 0.2409 & 0.0422 & 0.0023 & 0.0000 \\
$\epsilon_{6}$ & 0.0000 & 0.0001 & 0.0053 & 0.0728 & 0.3102 & 0.4140 & 0.1739 & 0.0227 & 0.0009 \\
$\epsilon_{7}$ & 0.0000 & 0.0000 & 0.0003 & 0.0113 & 0.1167 & 0.3716 & 0.3716 & 0.1167 & 0.0117 \\
$\epsilon_{8}$ & 0.0000 & 0.0000 & 0.0000 & 0.0009 & 0.0227 & 0.1739 & 0.4140 & 0.3102 & 0.0782 \\
$\epsilon_{9}$ & 0.0000 & 0.0000 & 0.0000 & 0.0000 & 0.0023 & 0.0422 & 0.2409 & 0.4292 & 0.2854 \\
\hline
\end{tabular}

Notes: This Markov chain is based on an autocorrelation coefficient of 0.75 and conditional standard deviation of 0.18. It was generated with Tauchen's (see Tauchen, 1986) discretization method and a width-parameter of 3.

Table 12: MARKov CHAin: Discount FACTOR

\begin{tabular}{cccc}
\hline \hline State & $\beta_{1}$ & $\beta_{2}$ & $\beta_{3}$ \\
Value & 0.94 & 0.96 & 0.98 \\
\hline$\beta_{1}$ & 0.9800 & 0.0200 & 0 \\
$\beta_{2}$ & 0.0025 & 0.9950 & 0.0025 \\
$\beta_{3}$ & 0 & 0.0200 & 0.9800 \\
\hline
\end{tabular}

\section{The calibration of $\theta$ :}

Baseline case and its three variants: $[\chi=0, \theta=0.78],[\chi=0.1, \theta=0.79],[\chi=0.2, \theta=0.795],[\chi=$ $0.3, \theta=0.805],[\chi=0.4, \theta=0.81],[\chi=0.5, \theta=0.815],[\chi=0.55, \theta=0.82],[\chi=0.6, \theta=0.82],[\chi=$ $0.7, \theta=0.83],[\chi=0.8, \theta=0.84],[\chi=0.9, \theta=0.85],[\chi=1.0, \theta=0.86]$.

Representative agent case: no lag: $\theta=0.78$, lag: $\theta=0.785$.

' $\frac{G}{Y}=0.225$ '-case and its three variants: $[\chi=0, \theta=0.665]$, $[\chi=0.1, \theta=0.675],[\chi=0.2, \theta=0.68]$, $[\chi=0.3, \theta=0.69],[\chi=0.4, \theta=0.70],[\chi=0.5, \theta=0.705],[\chi=0.6, \theta=0.715],[\chi=0.65, \theta=$ $0.72],[\chi=0.7, \theta=0.725],[\chi=0.8, \theta=0.735],[\chi=0.9, \theta=0.745],[\chi=1.0, \theta=0.76]$.

'Majority voting'-case and its three variants: $[\chi=0, \theta=0.76],[\chi=0.1, \theta=0.765],[\chi=0.2, \theta=$ 0.77], $[\chi=0.3, \theta=0.775]$, $[\chi=0.4, \theta=0.78]$, $[\chi=0.5, \theta=0.785],[\chi=0.6, \theta=0.795],[\chi=0.7, \theta=$ $0.805],[\chi=0.75, \theta=0.815],[\chi=0.79, \theta=0.82],[\chi=0.8, \theta=0.82],[\chi=0.9, \theta=0.835],[\chi=1.0, \theta=$ $0.85]$. 


\section{F Numerics - Appendix}

Table 13: Krusell-Smith Rules For Average CAPITAL - Equation(9)

\begin{tabular}{|c|c|c|c|c|c|c|}
\hline$z$ & $a_{0}$ & $a_{1}$ & $a_{2}$ & $a_{3}$ & $a_{4}$ & $R 2$ \\
\hline \multicolumn{7}{|c|}{ Baseline Case, $\theta=0.815, \chi=0.55$} \\
\hline$z_{1}$ & -0.2873 & 0.9079 & 0.0354 & -0.1754 & -0.0233 & 0.9994 \\
\hline$z_{2}$ & -0.2685 & 0.9024 & 0.0256 & -0.1707 & -0.0227 & 0.9995 \\
\hline$z_{3}$ & -0.2502 & 0.8972 & 0.0199 & -0.1670 & -0.0222 & 0.9995 \\
\hline$z_{4}$ & -0.2265 & 0.8941 & 0.0202 & -0.1611 & -0.0215 & 0.9995 \\
\hline$z_{5}$ & -0.1999 & 0.8976 & 0.0362 & -0.1554 & -0.0207 & 0.9995 \\
\hline \multicolumn{7}{|c|}{ Baseline Case, $\theta=0.815, \chi=0.55$, No Gini } \\
\hline$z_{1}$ & -0.2958 & 0.8959 & - & -0.1764 & -0.0234 & 0.9994 \\
\hline$z_{2}$ & -0.2749 & 0.8941 & - & -0.1717 & -0.0228 & 0.9995 \\
\hline$z_{3}$ & -0.2550 & 0.8897 & - & -0.1679 & -0.0223 & 0.9994 \\
\hline$z_{4}$ & -0.2309 & 0.8859 & - & -0.1618 & -0.0215 & 0.9995 \\
\hline$z_{5}$ & -0.2068 & 0.8819 & - & -0.1559 & -0.0208 & 0.9994 \\
\hline \multicolumn{7}{|c|}{ Representative Agent Case - No Lags } \\
\hline$z_{1}$ & -0.4495 & 0.9102 & - & -0.2698 & -0.0397 & 0.9994 \\
\hline$z_{2}$ & -0.4188 & 0.9061 & - & -0.2589 & -0.0381 & 0.9994 \\
\hline$z_{3}$ & -0.3916 & 0.9017 & - & -0.2503 & -0.0368 & 0.9994 \\
\hline$z_{4}$ & -0.3595 & 0.8981 & - & -0.2389 & -0.0351 & 0.9995 \\
\hline$z_{5}$ & -0.3288 & 0.8941 & - & -0.2289 & -0.0337 & 0.9995 \\
\hline \multicolumn{7}{|c|}{$G$-calibration, $\theta=0.72, \chi=0.65$} \\
\hline$z_{1}$ & -0.3810 & 0.9167 & 0.0369 & -0.2509 & -0.0366 & 0.9996 \\
\hline$z_{2}$ & -0.3578 & 0.9113 & 0.0286 & -0.2434 & -0.0356 & 0.9995 \\
\hline$z_{3}$ & -0.3358 & 0.9056 & 0.0233 & -0.2373 & -0.0347 & 0.9995 \\
\hline$z_{4}$ & -0.3062 & 0.9019 & 0.0236 & -0.2273 & -0.0333 & 0.9995 \\
\hline$z_{5}$ & -0.2747 & 0.9032 & 0.0354 & -0.2182 & -0.0319 & 0.9996 \\
\hline \multicolumn{7}{|c|}{ Majority Voting Case, $\theta=0.82, \chi=0.79$} \\
\hline$z_{1}$ & -0.2834 & 0.9091 & 0.0460 & -0.1749 & -0.0232 & 0.9994 \\
\hline$z_{2}$ & -0.2655 & 0.9023 & 0.0328 & -0.1702 & -0.0226 & 0.9995 \\
\hline$z_{3}$ & -0.2479 & 0.8960 & 0.0236 & -0.1665 & -0.0222 & 0.9995 \\
\hline$z_{4}$ & -0.2246 & 0.8923 & 0.0218 & -0.1604 & -0.0214 & 0.9995 \\
\hline$z_{5}$ & -0.1977 & 0.8962 & 0.0388 & -0.1546 & -0.0206 & 0.9995 \\
\hline
\end{tabular}

Notes: $z$ denotes aggregate productivity, which can achieve five discrete states: $z_{1}$ to $z_{5}$, Table 10 in Appendix E. The KS equation for average capital is given by: $\log K^{\prime}=a_{0}(z)+a_{1}(z) \log K+a_{2}(z) \log \operatorname{Gini}(k)+a_{3}(z) \log G+a_{4}(z)(\log G)^{2}$. 
Table 14: KRUSELl-SMith Rules FOR Gini(k) - EQUATION(10)

\begin{tabular}{cccccc|c}
\hline \hline$z$ & $\widetilde{a}_{0}$ & $\widetilde{a}_{1}$ & $\widetilde{a}_{2}$ & $\widetilde{a}_{3}$ & $\widetilde{a}_{4}$ & $R 2$ \\
\hline$z_{1}$ & 0.1215 & 0.0266 & 0.9778 & 0.0741 & 0.0096 & 0.9995 \\
$z_{2}$ & 0.1168 & 0.0230 & 0.9724 & 0.0744 & 0.0097 & 0.9993 \\
$z_{3}$ & 0.1145 & 0.0257 & 0.9807 & 0.0747 & 0.0098 & 0.9994 \\
$z_{4}$ & 0.1127 & 0.0327 & 1.0013 & 0.0739 & 0.0097 & 0.9994 \\
$z_{5}$ & 0.1060 & 0.0348 & 1.0049 & 0.0726 & 0.0096 & 0.9993 \\
\hline \multicolumn{6}{c}{$G$-calibration, $\theta=0.72, \chi=0.65$} \\
\hline$z_{1}$ & 0.1582 & 0.0213 & 0.9755 & 0.1047 & 0.0147 & 0.9997 \\
$z_{2}$ & 0.1536 & 0.0179 & 0.9712 & 0.1059 & 0.0150 & 0.9995 \\
$z_{3}$ & 0.1508 & 0.0201 & 0.9783 & 0.1063 & 0.0152 & 0.9995 \\
$z_{4}$ & 0.1477 & 0.0267 & 0.9968 & 0.1047 & 0.0151 & 0.9995 \\
$z_{5}$ & 0.1409 & 0.0313 & 1.0056 & 0.1027 & 0.0148 & 0.9995 \\
\hline \multicolumn{7}{c}{ Majority Voting Case, $\theta=0.82, \chi=0.79$} \\
\hline$z_{1}$ & 0.1186 & 0.0257 & 0.9694 & 0.0739 & 0.0096 & 0.9994 \\
$z_{2}$ & 0.1144 & 0.0233 & 0.9668 & 0.0740 & 0.0096 & 0.9993 \\
$z_{3}$ & 0.1126 & 0.0268 & 0.9779 & 0.0742 & 0.0097 & 0.9993 \\
$z_{4}$ & 0.1117 & 0.0348 & 1.0021 & 0.0733 & 0.0096 & 0.9994 \\
$z_{5}$ & 0.1050 & 0.0367 & 1.0059 & 0.0719 & 0.0095 & 0.9993 \\
\hline
\end{tabular}

Notes: $z$ denotes aggregate productivity, which can achieve five discrete states: $z_{1}$ to $z_{5}$, Table 10 in Appendix E. The KS equation for the natural logarithm of the Gini coefficient of capital is given by: $\log \operatorname{Gini}\left(k^{\prime}\right)=\widetilde{a}_{0}(z)+\widetilde{a}_{1}(z) \log K+$ $\widetilde{a}_{2}(z) \log \operatorname{Gini}(k)+\widetilde{a}_{3}(z) \log G+\widetilde{a}_{4}(z)(\log G)^{2}$. 
Table 15: Krusell-Smith Rules for Government Purchases - EQuation(11)

\begin{tabular}{|c|c|c|c|c|}
\hline 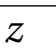 & 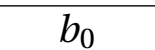 & 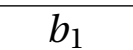 & $\overline{b_{2}}$ & $\overline{R 2}$ \\
\hline & \multicolumn{4}{|c|}{ Baseline Case, $\theta=0.815, \chi=0.55$} \\
\hline$z_{1}$ & -2.5786 & 0.6471 & 0.2629 & 0.9961 \\
\hline$z_{2}$ & -2.5707 & 0.6794 & 0.2993 & 0.9983 \\
\hline$z_{3}$ & -2.5745 & 0.6866 & 0.2673 & 0.9984 \\
\hline$z_{4}$ & -2.5947 & 0.6701 & 0.1741 & 0.9991 \\
\hline \multirow[t]{2}{*}{$z_{5}$} & -2.6108 & 0.6159 & 0.0540 & 0.9994 \\
\hline & \multicolumn{4}{|c|}{ Baseline Case, $\theta=0.815, \chi=0.55$, No Gini } \\
\hline$z_{1}$ & -2.6105 & 0.5574 & - & 0.9854 \\
\hline$z_{2}$ & -2.6073 & 0.5726 & - & 0.9928 \\
\hline$z_{3}$ & -2.6000 & 0.5726 & - & 0.9940 \\
\hline$z_{4}$ & -2.5974 & 0.5803 & - & 0.9968 \\
\hline \multirow[t]{2}{*}{$z_{5}$} & -2.5870 & 0.5667 & - & 0.9990 \\
\hline & \multicolumn{4}{|c|}{ Representative Agent Case - No Lags } \\
\hline$z_{1}$ & -2.6424 & 0.4910 & - & 1.0000 \\
\hline$z_{2}$ & -2.6205 & 0.4901 & - & 1.0000 \\
\hline$z_{3}$ & -2.5985 & 0.4867 & - & 1.0000 \\
\hline$z_{4}$ & -2.5751 & 0.4878 & - & 1.0000 \\
\hline \multirow[t]{2}{*}{$z_{5}$} & -2.5527 & 0.4904 & - & 1.0000 \\
\hline & \multicolumn{4}{|c|}{$G$-calibration, $\theta=0.72, \chi=0.65$} \\
\hline$z_{1}$ & -2.1162 & 0.6137 & 0.3288 & 0.9982 \\
\hline$z_{2}$ & -2.1142 & 0.6410 & 0.3349 & 0.9991 \\
\hline$z_{3}$ & -2.1197 & 0.6536 & 0.2986 & 0.9992 \\
\hline$z_{4}$ & -2.1372 & 0.6546 & 0.2313 & 0.9995 \\
\hline \multirow[t]{2}{*}{$z_{5}$} & -2.1631 & 0.6030 & 0.1069 & 0.9997 \\
\hline & \multicolumn{4}{|c|}{ Majority Voting Case, $\theta=0.82, \chi=0.79$} \\
\hline$z_{1}$ & -2.3470 & 0.6667 & 1.0967 & 0.8959 \\
\hline$z_{2}$ & -2.3941 & 0.6263 & 0.8867 & 0.9457 \\
\hline$z_{3}$ & -2.4863 & 0.5231 & 0.4543 & 0.9594 \\
\hline$z_{4}$ & -2.5528 & 0.4593 & 0.1591 & 0.9722 \\
\hline$z_{5}$ & -2.5808 & 0.3989 & -0.0098 & 0.9829 \\
\hline
\end{tabular}

Notes: $z$ denotes aggregate productivity, which can achieve five discrete states: $z_{1}$ to $z_{5}$, Table 10 in Appendix E. The KS equation for government purchases is given by: $\log G=b_{0}(z)+b_{1}(z) \log K+b_{2}(z) \log \operatorname{Gini}(k)$. 